\title{
Geomagnetic disturbances on ground associated with particle precipitation during $\mathrm{SC}$
}

\author{
V. Safargaleev ${ }^{1}$, A. Kozlovsky ${ }^{2}$, F. Honary ${ }^{3}$, A. Voronin ${ }^{1}$, and T. Turunen ${ }^{2}$ \\ ${ }^{1}$ Polar Geophysical Institute, Apatity, 184200, Russia \\ ${ }^{2}$ Sodankylä Geophysical Observatory, Sodankylä, 99600, Finland \\ ${ }^{3}$ Department of Communications Systems, Lancaster University, Lancaster, LA1 4WA, UK
}

Received: 20 October 2009 - Revised: 25 December 2009 - Accepted: 4 January 2010 - Published: 22 January 2010

\begin{abstract}
We have examined several cases of magnetosphere compression by solar wind pressure pulses using a set of instruments located in the noon sector of auroral zone. We have found that the increase in riometric absorption (sudden commencement absorption, SCA) occurred simultaneously with the beginning of negative or positive magnetic variations and broadband enhancement of magnetic activity in the frequency range above $0.1 \mathrm{~Hz}$. Since magnetic variations were observed before the step-like increase of magnetic field at equatorial station (main impulse, MI), the negative declinations resembled the so-called preliminary impulse, PI. In this paper a mechanism for the generation of PI is introduced whereby PI's generation is linked to SCA - associated precipitation and the local enhancement of ionospheric conductivity leading to the reconstruction of the ionospheric current system prior to MI. Calculation showed that PI polarity depends on orientation of the background electric field and location of the observation point relative to ionospheric irregularity. For one case of direct measurements of electric field in the place where the ionospheric irregularity was present, the sign of calculated disturbance corresponded to the observed one. High-resolution measurements on IRIS facility and meridional chain of the induction magnetometers are utilized for the accurate timing of the impact of solar wind irregularity on the magnetopause.
\end{abstract}

Keywords. Magnetospheric physics (Solar windmagnetosphere interactions)

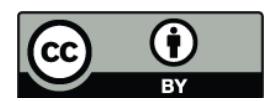

Correspondence to: V. Safargaleev (vladimir.safargaleev@pgia.ru)

\section{Introduction}

The geomagnetic sudden commencement (SC) is a very global phenomenon. Due to clear onset and well identified source, which is the sudden increase in the solar wind dynamic pressure at interplanetary shocks and discontinuities, the SC-associated events may serve as a diagnostic tool for the magnetosphere and continue to attract scientific interest.

The sudden magnetospheric compression by solar wind pressure pulse (SWPP) produces a variety of geophysical phenomena which may be easily detected with both ground based and on-board instruments. It is well established that the solar wind pressure pulse is associated with a step-like increase of the geomagnetic $\mathrm{H}$-component at low latitudes (e.g. Araki, 1994), pulsations of Pc 5 and Pc 1 frequency ranges at higher latitudes (e.g., Saito and Matsushita, 1967; Tepley and Wentworth, 1962), the enhancement of ionospheric absorption (e.g., Ranta and Ranta, 1990) and the intensification of electron and proton auroras (e.g., Brittnacher et al., 2000; Hubert et al., 2003). These effects and inter-relations between them are studied in the present paper.

The ground global magnetic response to SWPP may be characterized briefly as following (Araki, 1994). In the low latitude region the waveform of the SC is approximately a step-function. This variation is positive, indicating the increase of geomagnetic field. Observations at higher latitudes show the SC as two successive pulses: the preliminary impulse (PI) and the main impulse (MI). The sign of PI may be different at different stations. The appropriate current system of PI was suggested by Araki et al. (1982).

Responding to SCs, magnetosphere can act as a cavity. Magnetic oscillations excited in the magnetospheric cavity are categorized in general as Pc 5 pulsations (150-600 s period, $2-7 \mathrm{mHz}$ frequency). To emphasize the connection with SC, these pulsations are sometimes referred to as Psc 5. Besides the expected pulsations of compressional

Published by Copernicus Publications on behalf of the European Geosciences Union. 
type, simultaneous Alfvén oscillations are detected both at the stationary orbit (Baumjohan et al., 1984) and at the Earth's surface (Tverskaya and Khorosheva, 1982). Multispacecraft measurements showed that a toroidal (Alfvén) mode is observed over a narrow range of L-shells whereas a poloidal (compressional or magnetoacoustic) wave has a much larger radial extent (Eriksson et al., 2006).

It is well known that that at the time of a sudden commencement a sudden burst of particle precipitations into Dregion occurs that gives rise to a short-lasting increase in riometer absorption, known as Sudden Commencement Absorption (SCA). Ortner et al. (1962) reported that SCAs were located around the central line of the auroral zone. Increased electron density at altitudes $80-100 \mathrm{~km}$ has also been detected by the EISCAT radar during several SC events (Yahnin et al., 1995; Manninen et al., 1996) indicating the wide energy range of precipitating electrons. The important point for our study is the SCA-associated changes of ionospheric electric field (Nielsen and Honary, 2000) and conductivity (Senior et al., 2007).

The auroral oval and polar cap ionosphere can be considered as a screen on which the magnetospheric processes become visible. Owning to that, auroral images taken from space may be applied for understanding of the global magnetospheric response to SWPP. In particular, it has been found that $\mathrm{SC}$ leads to enhancement of the electron auroras. Inside the auroral oval, the intensification first occurs in the dayside and then expands toward the dawn and dusk (Zhou and Tsurutani, 1999; Kozlovsky et al., 2004). Liou et al. (2002) reported sudden brightening of the electron auroral patch separated from the main (pre-existing) auroral oval. This kind of auroral response to SWPP was named as Midday Sub-auroral Patches (MSPs). The similar effects were found in proton auroras by Hubert et al. (2003) and Fuselier et al. (2004) and were named "subauroral proton flashes" and "transient dayside subauroral proton precipitation".

Among the above listed SC-associated events, the preliminary impulse and excitation of the Alfvén-like oscillations are the most intriguing ones. Although the PI is clearly seen on the ground, it is not detected in interplanetary space. The excitation of the Alfvén waves implies the transformation of the energy of the initial compression (magnetoacoustic) disturbance to the Alfvén mode that is not possible theoretically in the uniform plasma.

The generation mechanisms for PI were suggested by Nishida (1964), Tamao (1964) and Araki (1977). In general, the mechanisms are based on the same idea - PI is caused by the incidence of MHD disturbance to the polar ionosphere. The disturbance is produced in the subsolar region of magnetopause at the very beginning of magnetosphere compression. To explain the advance of the main impulse, one should hypothesize the disturbance to propagate faster than magnetoacoustic wave responsible for the MI.

Transformation of the magnetoacoustic wave into the Alfvén mode is a more fundamental problem than generation of the PI and has been discussed therefore in many papers. The basic idea is that the magnetosphere is a non-uniform medium which leads to the coupling of these two modes (e.g. Hasegawa and Chen, 1974). However, why during SC the coupling occurs in the narrow range of L-shells is not well understood.

Note that in the studies mentioned the source is regarded to be the same for the PI and Alfvén oscillations, as well as for the main impulse. That is a front of compressional disturbance propagating Earthward at the velocity of magnetoacoustic wave. Safargaleev and Maltsev (1987) suggested that the source of PI and Alfvén oscillations may be the same but different from that for the MI. They supposed that it could be the localized area of enhanced ionospheric conductivity. In the presence of ionospheric electric field, the appearance of ionospheric irregularity "launches" Alfvén wave through the well-known polarization effect. Velocity of precipitating particles producing the ionospheric irregularity is much higher than that for magnetoacoustic wave. Therefore Alfvén oscillations will start on the ground slightly prior to the arrival of the front of compressional disturbance (main impulse). Superposition of oscillations and MI creates the effect of high latitude preliminary impulse. Safargaleev and Maltsev also showed that the disturbance of the current system caused by the local enhancement of the ionospheric conductivity resembles the equivalent current system of the preliminary impulse obtained by Araki et al. (1982).

In this study we perform a comparative analysis of magnetic and riometric absorption disturbances caused by SC with the aim to test the hypothesis by Safargaleev and Maltsev (1987) on the ionospheric origin of preliminary impulse and SC-associated Alfvén oscillations at high latitudes. We use the data of Scandinavian magnetometers network IMAGE to identify the sudden commencements with preliminary impulse. As indirect evidence for the SCinitiated enhancement of ionospheric conductivity we regard the above mentioned SCA events inferred from the data of the Kilpisjärvi IRIS imaging riometer. We only consider the local near-noon events since the interaction between solar wind and Earth's magnetosphere is more direct in the noon sector. We do not discuss the later stage of development of the events (after the front of disturbance arrives to the Earth). Otherwise we should take into account the IMF effects and complex character of propagation in the magnetosphere of different MHD-modes launched by SWPP. In the light of our findings, we make recommendations on the use of SC-excited Pc 1 pulsations in the tasks of magnetospheric physics.

\section{Instrumentation and interval selection}

Northern Scandinavia is located under the auroral oval and is a region where the SC-initiated precipitation and accompanying events may be detected by a number of instruments. 


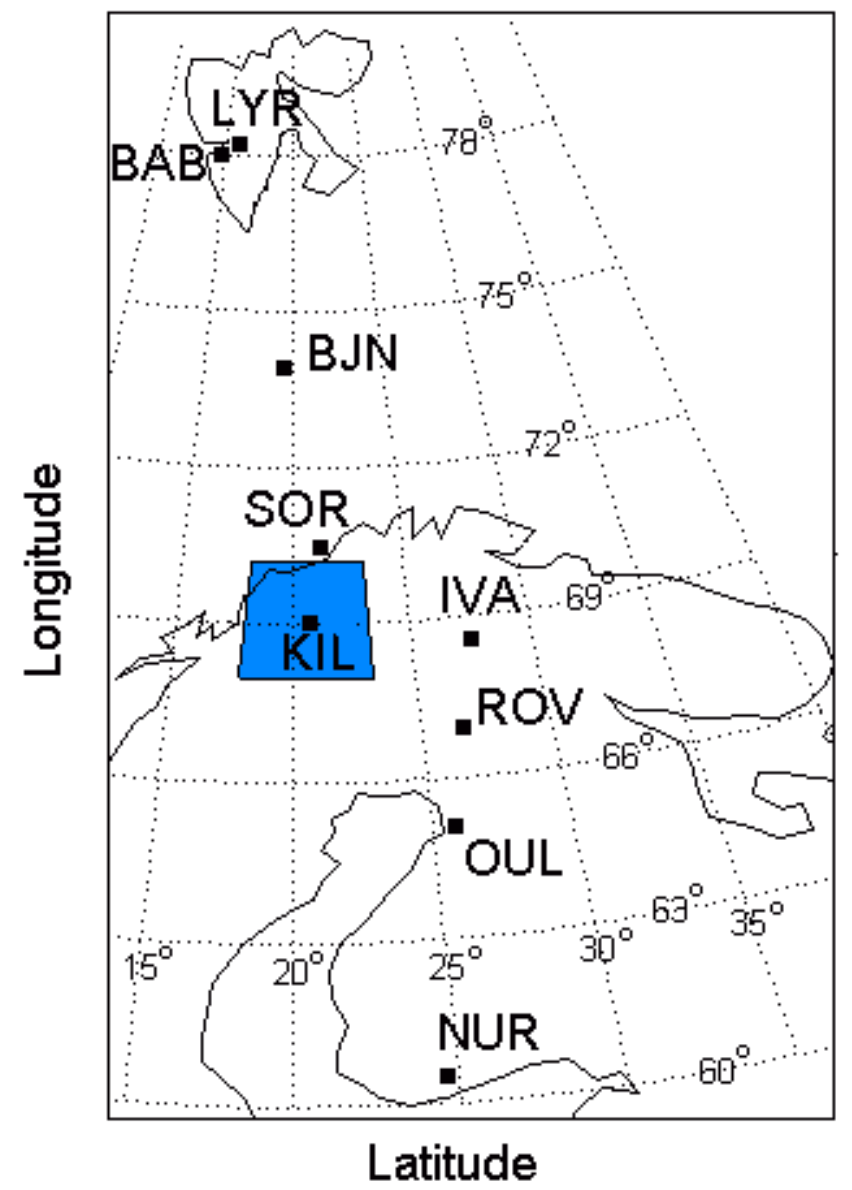

Fig. 1. Location of the instruments in the region of observations. Blue area is field of view of the imaging riometer IRIS facility.

Of particular interest to our study are riometers and magnetometers.

Figure 1 shows the location of measurement points in this study. The Kilpisjärvi IRIS imaging riometer $\left(69.05^{\circ} \mathrm{N}\right.$, $20.79^{\circ} \mathrm{E}, \mathrm{MLT}=\mathrm{UT}+\sim 2 \mathrm{~h}$ ) provides cosmic radio noise absorption at $38 \mathrm{MHz}$. The system produces an array of 49 narrow beams with widths between $13^{\circ}$ and $16^{\circ}$. The IMAGE chain of magnetometers covers roughly magnetic latitudes $55^{\circ}-75^{\circ}$. The meridional middle chain of IMAGE is particularly suitable for electrojet studies. In longitudinal direction the coverage is best in the standard auroral oval region $\left(64^{\circ}-67^{\circ}\right.$ magnetic latitudes). Currently the network includes 29 magnetometers with sampling rate of $10 \mathrm{~s}$. Finnish pulsation magnetometer chain contains six three-component search coil magnetometer stations located on Scandinavian Peninsula. In addition, the station of the Polar Geophysical Institute, Russia, at Barentsburg (BAB) was used. Stations are timed by GPS system and sampling rate of the data of induction magnetometer is $40 \mathrm{~Hz}$.

Statistically, the most direct response of the ionosphere to the impact of solar wind irregularity to the magnetopause is assumed to be observed around the noon-sector. Close to the dawn and dusk, the propagation of the disturbances both in the magnetosphere and ionosphere should be taken into account. To exclude the propagating effects, we concentrate mainly on the events within $\sim 6 \mathrm{~h}$ interval centered near local noon at Kilpisjärvi (MLT=UT+ $\sim 2 \mathrm{~h} 40 \mathrm{~m}$ ).

Typical amplitude of fluctuations in solar wind dynamic pressure is $0.5-1 \mathrm{nPa}$. We limited ourselves by considering the SCs with magnitude notably exceeded this value (except one event that occurred under the quite conditions in solar wind and produced well manifested response on the ground). Note, that well recognized response to SC in riometric and magnetic data was one of the limitations on the event selection.

To define the moment of main impulse we used the data from magnetic equatorial stations Bangui (BNG, $4.33^{\circ} \mathrm{N}, 18.57^{\circ} \mathrm{E}, \mathrm{MLT}=\mathrm{UT}+2 \mathrm{~h}$ ) and Addis Abbaba (AAE, $9.02^{\circ} \mathrm{N}, 38.77^{\circ} \mathrm{E}, \mathrm{MLT}=\mathrm{UT}+2 \mathrm{~h}$ ). Using these data for comparison with others, a higher time resolution samples of $30 \mathrm{~s}$ before and after the minute (IAGA format) was chosen. Only events with clear onset were accepted. The events with weak negative excursion prior to $1 \mathrm{~min}$ step-like increase (low latitude preliminary impulse) were also excluded from the consideration.

We have examined the Wind data on solar wind ion pressure through the period from June 2000 to April 2004. Although more than 200 SCs were analyzed altogether, only 11 events meeting the above formulated criteria were found and undergone the further analysis. In the next section a typical event observed on 18 March 2002 is described in details, and analysis of all the events is summarized in Sect. 4.

3 Geomagnetic disturbances associated with particle precipitation initiated by sudden increase in solar wind dynamic pressure: a case study

\subsection{Sudden magnetosphere compression on 18 March 2002: general description of the event}

Figure 2 is an overview of the disturbances occurred on the ground in response to strong increase in solar wind dynamic pressure. At about 13:10 UT the Wind satellite, probing the interplanetary medium at $X_{\mathrm{GSM}}=44 R_{\mathrm{E}}, Y_{\mathrm{GSM}}=-117 R_{\mathrm{E}}$, and $Z_{\mathrm{GSM}}=-34 R_{\mathrm{E}}$, observed the increase of solar wind pressure up to $\sim 23 \mathrm{nPa}$ within five minute interval (top panel in Fig. 2a). We should note that this significantly exceeded the typical amplitude of variations of solar wind pressure. 12 min later, main impulse was detected at low latitudes (AAE). The time lag corresponds approximately to the propagation time of the front of irregularity from satellite position to the magnetopause. Rather complex magnetic variations were seen at IMAGE magnetometer network (middle panel in Fig. 2a). In auroral zone (KIL) and below (NUR), the disturbance in geomagnetic $\mathrm{X}$-component has a shape of a step 


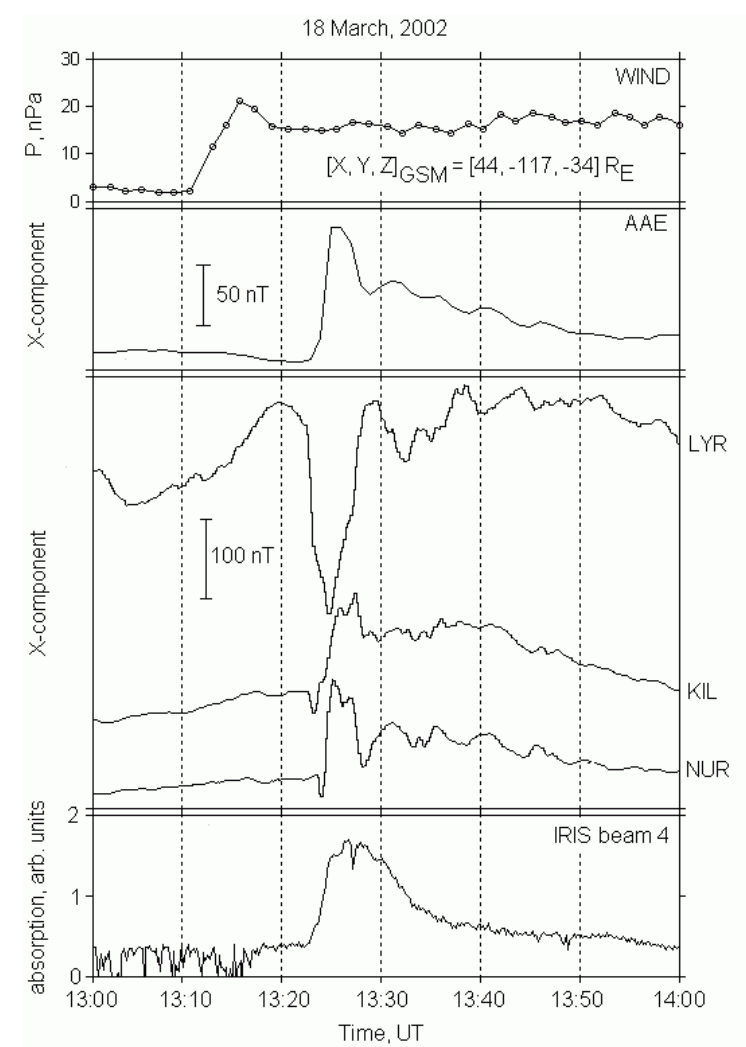

a

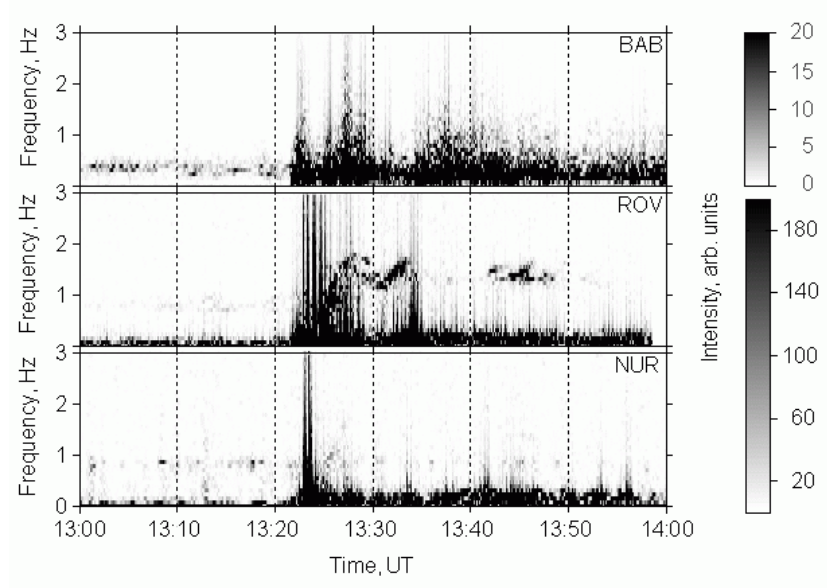

b

Fig. 2. (a) From top to bottom: solar win pressure pulse (SWPP) in space, magnetic response at equatorial station and in auroral zone, sudden absorption commencement (SCA); (b) sonograms showing the SWPP-initiated magnetic disturbances on the meridional chain of induction magnetometers.

with negative preliminary impulse. One can also distinguish Pc 5 pulsations at NUR. At high latitudes (LYR) the SWPP caused strong negative excursion. These magnetic variations were accompanied with enhancement in riometric absorption seen in almost all beams of imaging riometer IRIS (Fig. 2a, bottom panel). 


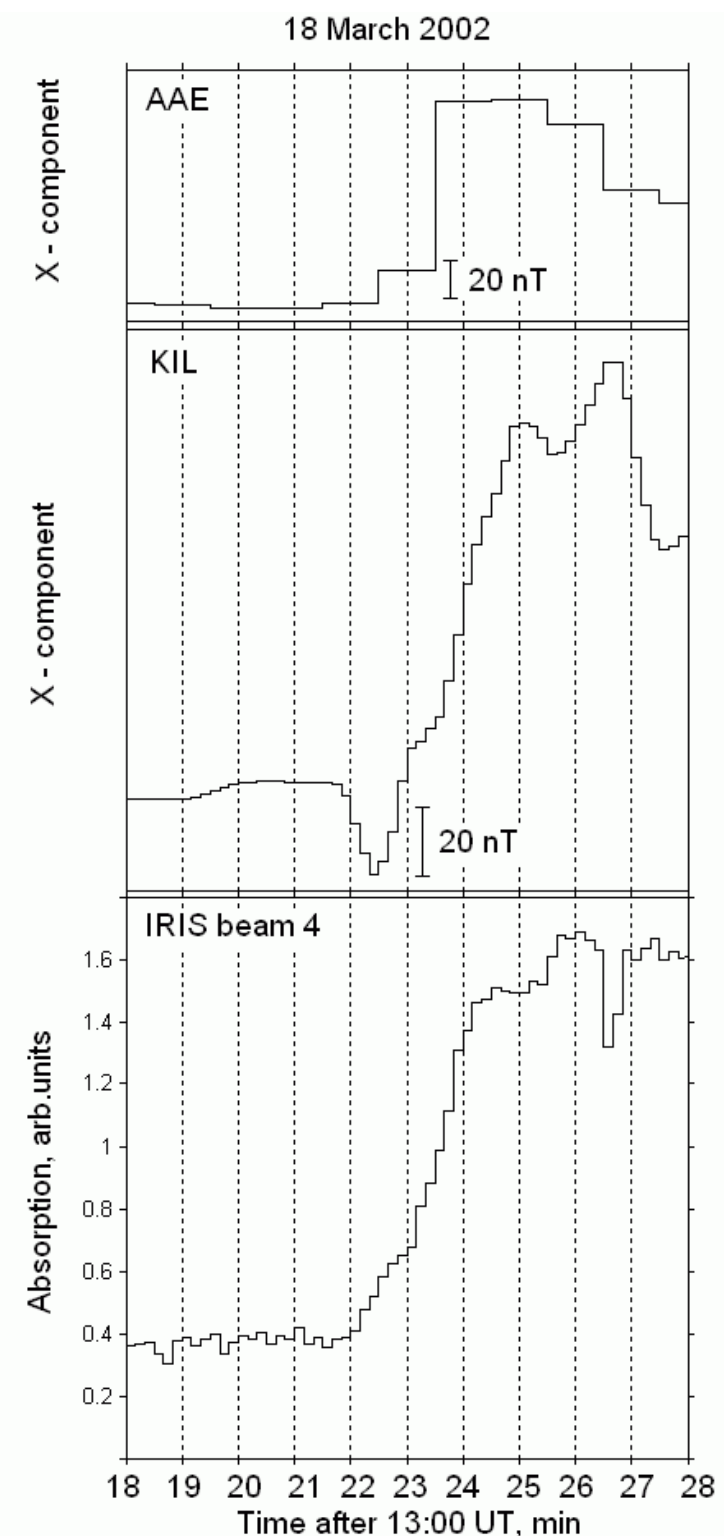

a

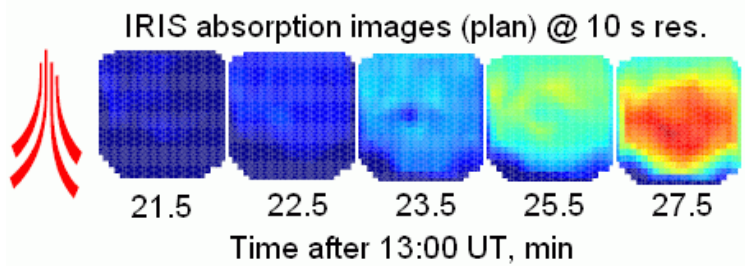

b

Fig. 4. (a) Negative magnetic deviation and SCA observed at high latitudes 1 min before the main impulse at equatorial station AAE; (b) two-dimensional "portrait" of sudden commencement absorption in the IRIS field of view.
The geomagnetic response in Pc 1 frequency range is shown on spectrograms in Fig. 2b. We point out three stages in the development of the ULF-activity. At first, the amplitude of variations in frequency range of $0-0.4 \mathrm{~Hz}$ increased suddenly in auroral zone (ROV) and at high-latitudes (BAB). Some minutes later, the enhancement of rising frequency occurred at ROV. Finally, the series of two ULF-bursts with central frequency $\sim 1.2 \mathrm{~Hz}$ and repetition period of about 12 min was detected in auroral zone.

Figure 3 shows the behavior of electron auroras initiated by sudden magnetosphere compression. The auroras enhanced near local noon and then split up in two bright patterns propagating to dawn and dusk inside the boundary plasma sheet (bps) as was indicated by data of the DMSP F13 satellite passing above the area of observations near 13:26 UT. The conjugation of the postnoon auroral oval with bps was reported earlier by Kozlovsky et al. (2002). While the riometric enhancement might be caused by the intensification of particle precipitation to ionospheric D-region, the enhancement of electron auroras indicate the increase of particle precipitation to E-region.

So, by taking into account the enhancement of proton auroras, which will be discussed later, the chosen event presents almost full set of SWPP accompanying phenomena listed in the Introduction section. In the following sections we discuss in the detail the possible connection of PI with electron precipitation and Pc 1 pulsations with precipitation of protons.

\subsection{Preliminary impulse and sudden commencements in riometric absorption and dayside electron auro- ras}

The SWPP associated phenomena are presented in Fig. 4 in more details. Magnetic data from low latitude station AAE has the lowest temporal resolution of 1 min whereas other data were obtained at $10 \mathrm{~s}$ resolution. Nevertheless, it is seen that disturbance at KIL started before the step increase of geomagnetic field at low latitudes (main impulse) and resembled a typical preliminary impulse. The AAE data are averaging higher time resolution samples from before and after the minute. In such a case, the MI at AAE corresponds to step increase of magnetic field at KIL, which also started near 13:23:30 UT.

The weak negative deviation at KIL (preliminary impulse) started almost simultaneously with enhancement in riometric absorption. In Introduction section this phenomenon was referred to as SCA. The enhancement occurred within the whole IRIS field of view, as seen in Fig. 4b, and indicated the increase of the precipitation of the electrons with energy of several tens of $\mathrm{keV}$. The SWPP initiated also more soft precipitation, which caused electron auroras (see Fig. 3). Although the temporal resolution of SIE instrument onboard the IMAGE satellite is one frame per two minutes, in the present case it was possible to find out that auroras appeared at 13:22:40 UT, i.e. before the main impulse had started on 


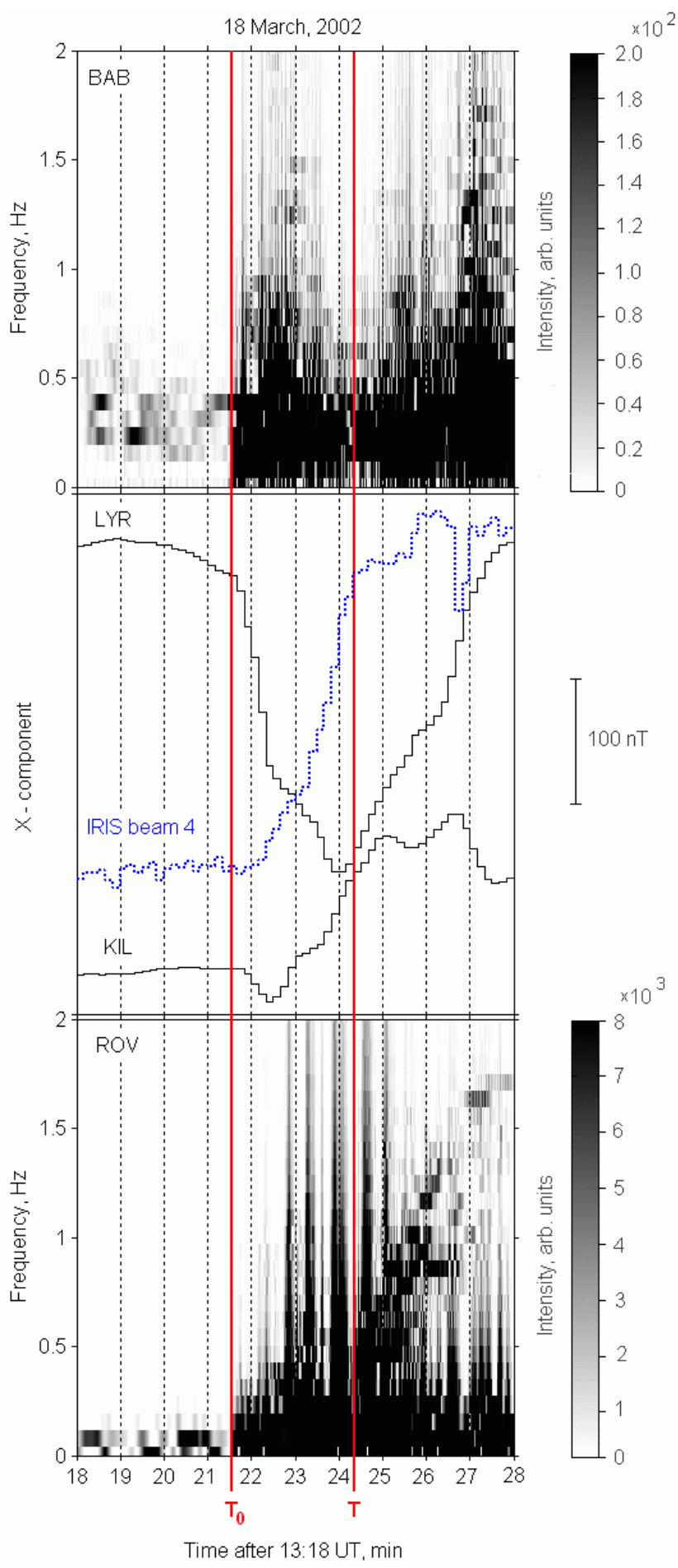

Fig. 5. Disturbances in the frequency band above $0.1 \mathrm{~Hz}$ (upper and lower panels) and SC-initiated magnetic variations at LIR and KIL and sudden commencement absorption (central panel).

the ground. Based on this observation, we use the riometer data to indicate precipitation in the wide energy range for the other SWPP events when IMAGE satellite data were not available.
Good temporal correlation PI with SCA indicates the connection between them. We think that precipitation could lead to reconfiguration of the ionospheric current system via the local increase of ionospheric conductivity. No doubts, electron auroras are accompanied with change of ionospheric conductivity. Recently Senior et al. (2007) showed that there is a relation between riometric absorption and the conductance, too. Since the particle velocity is higher than the velocity of magnetoacoustic MHD wave responsible for MI, the changes of ionospheric currents starts earlier than the wave arrives at Earth. Thus, the precipitation produces on the ground an imaginary effect equivalent to the preliminary impulse. Note also, that local area of enhanced conductivity may be a source of Alfvén wave (e.g. Kozlovsky et al., 1997), the signatures of which are seen in Fig. 4 as pulsations of $100 \mathrm{~s}$ period at KIL.

At the initial stage of the event the amplitudes of both PI and SCA are small. At this time the enhanced auroras are observed in post-noon sector (see Fig. 3), away from Kilpisjarvi. The magnetic disturbance reached maximum at 13:27 UT, when the area of enhanced luminosity has shifted close to the region of observations. The intensities of both auroras and SCA are also higher at this moment. This also supports our assumption on the possible source of preliminary impulse.

\subsection{Bursts of ULF noise and dayside proton auroras}

The sonograms in Fig. 5 show in the detail the initial stage of SWPP-induced ULF activity at high latitudes (BAB) and in auroral zone (ROV). First of all, we draw reader's attention to the burst of increasing frequency (further referred as "rising bursts") started at 13:24:20 UT at ROV (moment $T$ in Fig. 5). Such kind of ULF activity, firstly described by Tepley and Wentworth (1962), seems to be the most typical geomagnetic response to the SWPP in the frequency range $0.1-3 \mathrm{~Hz}$ (e.g. Kangas et al., 1998). This feature is associated with the development of electromagnetic ion-cyclotron (EMIC) instability in the equatorial plane of magnetosphere near the noon. In the present case, the source of the rising burst in the magnetosphere is also limited in radial direction and seems to be conjugated with auroral zone, because no response is seen $\sim 800 \mathrm{~km}$ north and south of Kevo (see Fig. 2b). In Fig. 6, where three intervals of activity of proton auroras are presented, the rising burst may be associated with the appearance of "subauroral proton flash" in postnoon sector between 13:22:40 UT and 13:24:43 UT (series of images in Fig. 6a). This is expected since EMIC instability should lead both to generation of the waves of Pc 1 type and proton precipitations.

Another form of ULF-response, which has also been previously mentioned in the literature (Safargaleev et al., 2002), is a series of two bursts at central frequency $\sim 1.2 \mathrm{~Hz}$ seen in the middle spectrogram in Fig. 2b after 13:30 UT and around 13:45 UT. As it is seen in Fig. $6 \mathrm{~b}$ and $\mathrm{c}$ these pulsations are 
18 March 2002 IMAGE SIP
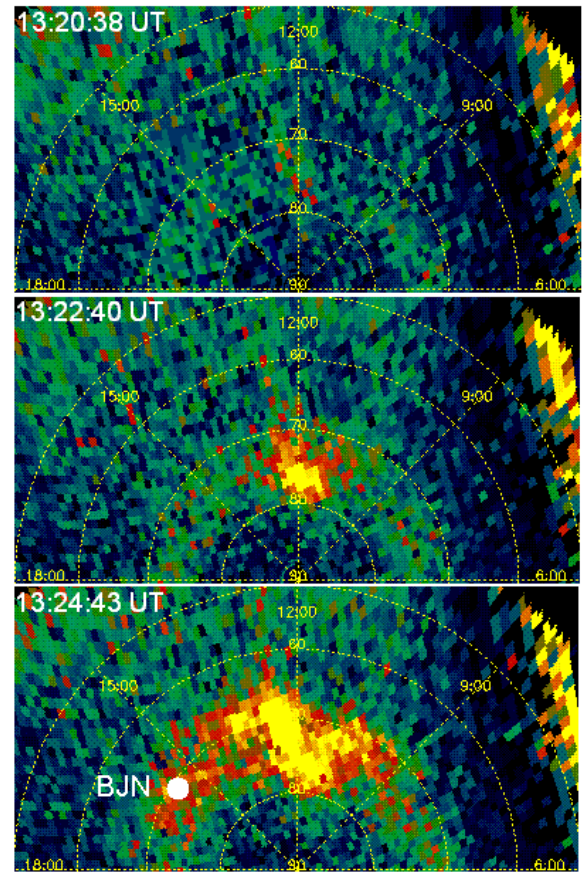

a
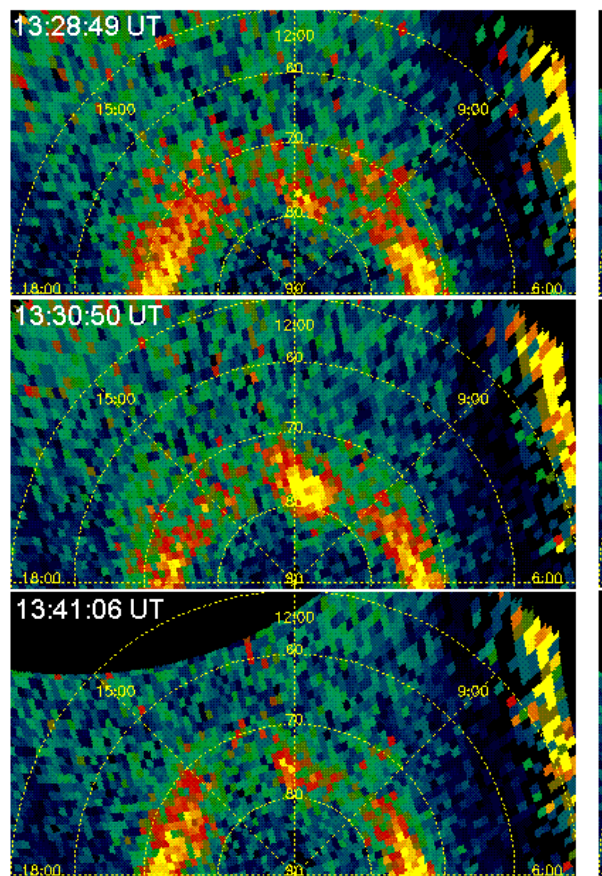

b
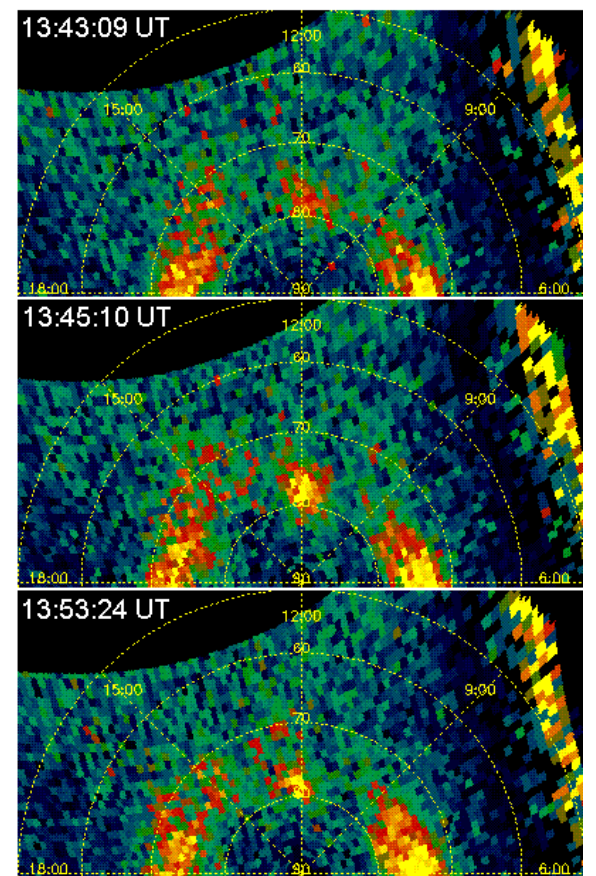

C

Fig. 6. Images showing three intensifications of proton auroras in the midday sector. Each of intensifications may be associated with enhancement of ULF activity at KIL (see Fig. 2b, central panel).

accompanied with proton aurora enhancements, too. Unlike the rising burst, these auroral flashes are observed at higher latitudes, presumably in the cusp vicinity. Note that other kind of proton auroras, expanding inside auroral oval toward the dawn and dusk, did not demonstrate apparent correlation with ULF-activity.

Sudden enhancement of ULF noise in the frequency range below $0.4 \mathrm{~Hz}$, which occurred almost simultaneously with SCA, at the moment $T_{0}=13: 21: 30 \mathrm{UT}$ (see Fig. 5), was not reported before as an attribute of SC-initiated ULF activity. The enhancement is seen at $\mathrm{BAB}, \mathrm{ROV}$ and NUR but is more impressive at $\mathrm{BAB}$, i.e. close to the latitudes where electron auroras appear in response to SWPP (Fig. 3) and magnetic disturbance was large (Fig. 2a). It is suggested that similar to preliminary impulse, this kind of ULF activity is also caused by the disturbances of ionospheric currents in the region of electron precipitation. Sudden ULF-enhancement gets ahead of rising burst by three minutes. The possible reasons for this will be discussed later in Sect. 4.4.

\section{Discussion}

\subsection{High latitude magnetic disturbances and sudden commencement in riometric absorption: statistics}

Characteristics of the events considered in this study are presented in Table 1. In the second column we indicate the date of SC. Amplitudes of SWPP in space (mainly, at the Wind satellite) and at low latitudes (mainly, at BNG observatory) are in third and sixth columns. The start times of magnetic disturbance in horizontal X-component at $\operatorname{KIL}(\Delta X)$ and SCassociated riometric disturbance (SCA) are in the seventh and tenth columns. Although all magnetic disturbances at high latitudes were observed before the disturbance at low latitude station, not all of them developed a negative preliminary impulse prior the step-like increase as shown in Fig. 4a. Hence, a general term "preliminary magnetic disturbance", PMD, instead of "preliminary impulse" is used in the following discussion which will be discussed later. Columns eight and eleven contain information about amplitude of the preliminary magnetic disturbance and SCA. In the ninth column, the period of two modes of SC-initiated pulsations, Psc 5, is given. The sign "-_" means that no pulsations were possible to identify in the data of IMAGE network.

We separate data set in two parts. For the events 1-6 in Table 1 the preliminary magnetic disturbance and SCA start simultaneously (within $10 \mathrm{~s}$ ambiguity due to data resolution). 
Table 1. Characteristics of SWPPs in space and associated magnetic and riometric disturbances on the ground.

\begin{tabular}{|c|c|c|c|c|c|c|c|c|c|c|}
\hline No. & Date & $\begin{array}{l}\text { SWPP } \\
(\mathrm{nPa})\end{array}$ & $\begin{array}{l}\text { IMF } B_{\text {ya }} \\
\quad(\mathrm{nT})\end{array}$ & $\begin{array}{l}\mathrm{IMF} B_{\mathrm{za}} \\
\quad(\mathrm{nT})\end{array}$ & $\begin{array}{l}\text { MI } \\
(\mathrm{nT})\end{array}$ & $\begin{array}{l}\Delta X \\
\mathrm{UT}\end{array}$ & $\begin{array}{c}\Delta X \\
\mathrm{nT}\end{array}$ & $\begin{array}{c}\text { Psc } 5 \\
\text { s }\end{array}$ & $\begin{array}{c}\text { IRIS } \\
\text { UT }\end{array}$ & $\begin{array}{c}\text { SCA } \\
\mathrm{dB}(\text { beam })\end{array}$ \\
\hline 1 & 2 & 3 & 4 & 5 & 6 & 7 & 8 & 9 & 10 & 11 \\
\hline 1 & 8 Jun 2000 & 10 & 2.5 & 4 & 55 & 09:10:20 & -125 & $150 / 50$ & 09:10:20 & $2.0(29)$ \\
\hline 2 & 6 Nov 2000 & 2 & 2.5 & -1.5 & 40 & 09:47:10 & +40 & $-/ 60$ & $09: 47: 10$ & $1.1(30)$ \\
\hline 3 & 19 Mar 2001 & 2 & -4.5 & 3 & 35 & $11: 12: 40$ & -30 & $-1-$ & $11: 12: 40$ & $0.5(8)$ \\
\hline 4 & 23 May 2002 & 11 & +12 & 5 & 40 & $10: 49: 50$ & -50 & $140 /-$ & $10: 49: 50$ & $1.2(3)$ \\
\hline 5 & 8 Apr 2001 & 12 & +4 & -2 & 55 & 11:00:50 & +50 & $-/ 60$ & 11:00:50 & $0.8(9)$ \\
\hline 6 & 19 Apr 2002 & 1.5 & -9 & 0 & 50 & 08:35:00 & +20 & $140 /-$ & 08:35:00 & $0.9(40)$ \\
\hline 7 & 3 Mar 2001 & 2 & 4 & -3 & 20 & $11: 21: 10$ & -20 & $140 /-$ & $11: 21: 30$ & $0.3(10)$ \\
\hline 8 & 17 Apr 2002 & 20 & -7 & -5 & 70 & 11:06:00 & +40 & $120 /-$ & 11:06:30 & $1.0(15)$ \\
\hline 9 & 17 Aug 2001 & 5 & 4 & 1.5 & 35 & $11: 02: 30$ & -30 & $-1-$ & $11: 05: 30$ & $0.7(22)$ \\
\hline 10 & 29 Jul 2002 & 4 & -3 & 1.5 & 25 & $13: 21$ & -70 & $130 /-$ & $13: 25$ & $1.0(17)$ \\
\hline 11 & 18 Mar 2002 & 20 & -2 & 0 & $100^{\mathrm{b}}$ & $13: 21: 50$ & -25 & $-1-$ & $13: 22: 10$ & $1.1(4)$ \\
\hline
\end{tabular}

a ACE data; ${ }^{b}$ AAE data

The observations refer mainly to near noon hours. The measurements during events 7-11 took place in the afternoon. For these events SCA is delayed relative to the start of preliminary magnetic disturbance by $20-180 \mathrm{~s}$. The delay may be explained in the frame of generation mechanism of PI suggested by Safargaleev and Maltsev (1987) and briefly discussed in previous section. Indeed, the SCA is seen when the precipitation occurs in the vicinity of riometer set whereas the magnetometers are sensitive to the disturbance of ionospheric current far away from the measurement point and, hence, can detect it prior to particle precipitation observed at IRIS.

For all events considered, the amplitude of preliminary magnetic disturbance decreased from KIL to lower latitudes (see, for example, Fig. 2a). This is consistent with our assumption regarding the localization of the ionospheric source of PMD at high latitudes. However, no systematic behavior was found form KIL to Spitsbergen Archipelago, probably, due to poor coverage by the ground measurements of this very interesting area, which is conjugated with various dayside magnetospheric domains (mantle, cusp, llbl, bps).

The variety of high latitude magnetic response to SWPP is demonstrated in Fig. 7. Some statistical results are presented in Fig. 8.

Six disturbances of eleven were negative and looked like a typical preliminary impulse whereas others were positive. Sometimes the disturbances of the opposite polarities were observed at the same place (KIL) and, approximately, at the same time (for instance, events 8 and 9 in the Table 1), which may not be explained by spatial distribution of the equivalent ionospheric current system of PI suggested by Araki et al. (1982). Figure 8a shows the dependence of the polarity of PMD on the sign of IMF $B_{Z}$ component averaged over the 30 min interval preceding the sudden enhancement of plasma density and bulk speed at ACE satellite. Most of the preliminary disturbances, which look like the typical preliminary impulse, started when $B_{\mathrm{Z}}$ was northward whereas prior positive PMD the IMF $B_{\mathrm{Z}}$ was directed southward. The sign of $B_{\mathrm{Z}}$ influences the configuration of the dayside magnetosphere, shifting, in particularity, the ionospheric projection of subsolar point poleward or equatorward via the reconnection process. Hence, the region of precipitation may also be shifted poleward or equatorward depending on the IMF $B_{\mathrm{Z}}$ sign.

In general, the shape of PMD may be described as superposition of damping oscillations and delayed by $1-2$ min the step-like increase of the magnetic field (Fig. 8b). Note that the shape of preliminary magnetic disturbance in Fig. 7 does not repeat the shape of the bay in riometric absorption. This finding means that beside the increase of the ionospheric conductivity, there should be another factor, which regulates the development of PMD in time. We think that this may be movement/expansion of the irregularity relative to the observation point.

Data presented in Fig. 8c show no correlation between the amplitudes of the roimetric disturbance and SWPP. For example, the strongest SCA was detected during event 1 when IRIS was near the noon. Rather larger pressure pulses (events 8 and 11) were accompanied with absorption enhancements, which are even weaker by factor of 2 . The measurements during these events were in the afternoon sector. It is therefore suggested that for the most of events the maximum precipitation occurred not just above the IRIS field of view but at some distance from it and then propagated/expanded toward the observation region (see Sect. 3.2 and Fig. 3) following the front of MHD disturbance in the magnetosphere. 

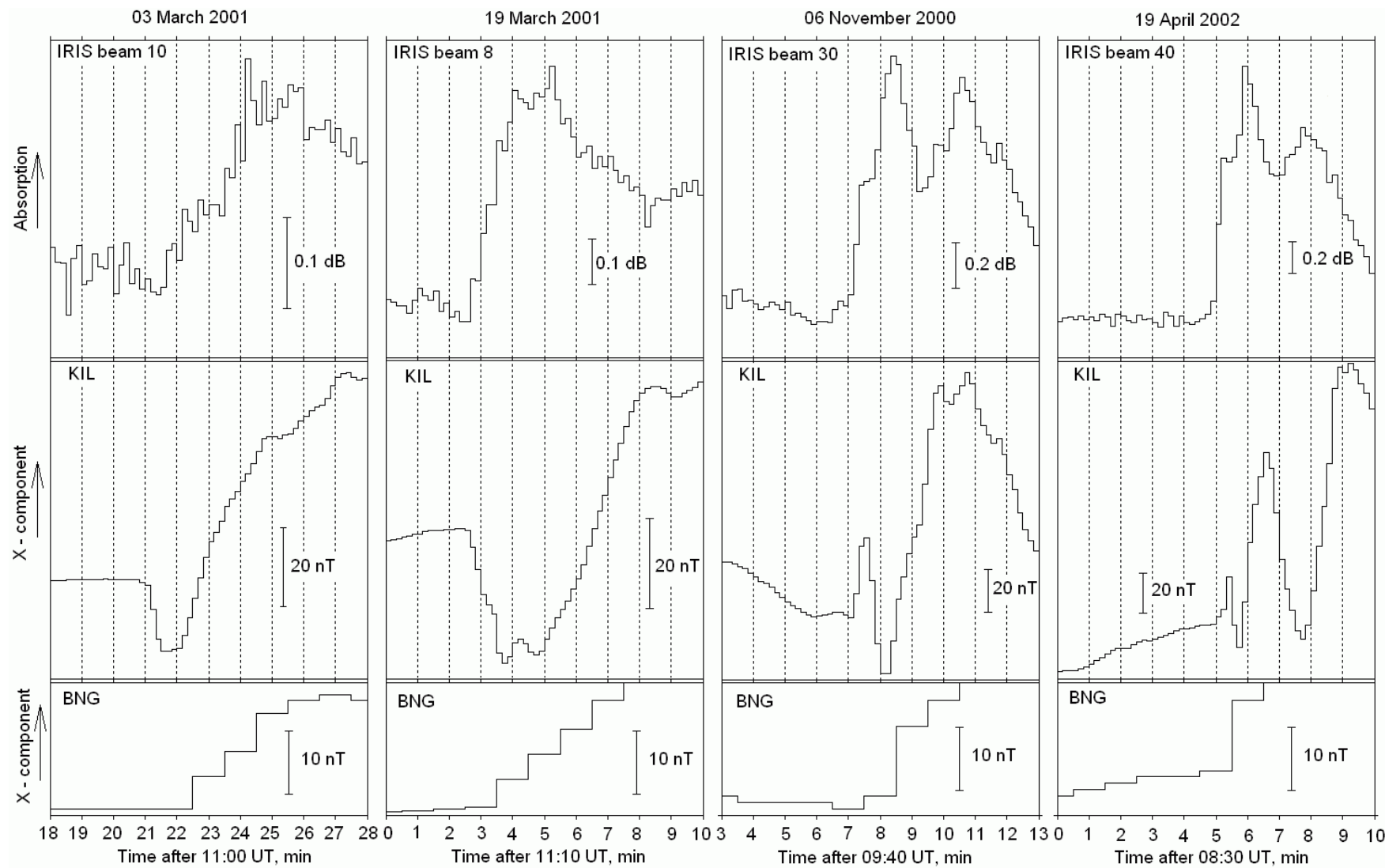

Fig. 7. Different shape of magnetic response to SWPP at high latitudes. Magnetic variation begins simultaneously with SCA event but forestalls the step-like disturbance at equatorial station.

In the next section we summarize the results of observations with emphasis on the main features of the preliminary magnetic disturbance. A simple semi-empirical model of disturbance will be discussed.

\subsection{Polarization electric fields generated by an elliptic ionospherc irregularity as a source of preliminary magnetic disturbance}

In this section we present a model of high latitude magnetic response to SWPP, which fits the following experimental results inferred from the data analysis.

1. Geomagnetic variation at high latitudes precedes the step-like increase of geomagnetic H-component at equatorial station.

2. Geomagnetic variation at high latitudes starts almost simultaneously with enhancement of the particle precipitation near the meridian plane where the solar wind discontinuity hits the magnetopause (near local noon). Otherwise, the increase of precipitation is delayed after the magnetic disturbance by $1-2 \mathrm{~min}$.
3. The magnetic disturbance looks like a superposition of oscillations and a step-like increase of the field, which is shifted by $1-2$ min relative to the oscillation onset. Herewith, the former are not accompanied with the variations in riometric absorption.

4. The oscillations start as positive or negative deviation depending on the orientation of IMF $B_{\mathrm{Z}}$ component. Positive response is observed when $B_{\mathrm{Z}}$ is negative before the event and vice versa.

For the most of recent models of PI, the general assumption is that the ionospheric currents responsible for PI are induced by the electric fields transported from the outer magnetosphere (Araki et al., 1994, and references therein). Fujita (2003) presented a quantitative model of the PI, where the PI current is first excited as an enhanced Chapman-Ferraro current in the magnetopause and then turns to the magnetosphere along the wavefront of the compressional signal launched by the impulse. To explain the main feature of PI, namely, its occurrence before the main impulse, such hypotheses as a difference of propagation velocity of SCinitiated waves along and across the magnetic field line, or complex shape of the dayside magnetosphere, or specific 
shape of the front of disturbance, should be assumed. Nevertheless, the generation mechanism for PI is still a point of debate (e.g. Kikuchi and Araki, 2002).

Safargaleev and Maltsev (1987) suggested that the ionospheric currents responsible for PI are induced by the electric fields, which appear in the ionosphere directly as the polarization fields inside and outside the localized area of enhanced conductivity. The ionospheric irregularity is produced by precipitating particles. In this model, the time shift between PI and step variation appears because the particles move in the magnetosphere faster then MHD waves and, hence, reach the ionosphere prior to the disturbance responsible for main impulse. The situation is similar to that observed in our study in riometric absorption (see examples in Figs. 4 and 7).

The theoretical details of generation and calculation of polarization electric field in the ionosphere may be found, for instance, in the papers devoted to excitation of $\mathrm{Pi} 2$ pulsations by brightening of auroral arc (Maltsev at al., 1974), generation of the Alfvén impulse in the ionosphere (Kozlovsky et al., 1997) and behavior of the electric field in the vicinity of varying auroras (Safargaleev et al., 2000). It was shown that the problem may be easily solved if one presents the ionosphere as a complex plane with real axis $\mathrm{x}$ directed to the East and imaginary axis y directed to the North. Within such approach, electric field vectors are presented as complex numbers like $\boldsymbol{E}=E_{\mathrm{x}}+i E_{\mathrm{y}}$, the independent complex variable (distance to the observation point) is defined as $z=x+i y$, and complex conductivity has a form $\Sigma=\Sigma_{\mathrm{P}}-i \Sigma_{\mathrm{H}}$, where $\Sigma_{\mathrm{P}}$ and $\Sigma_{\mathrm{H}}$ are the height-integrated Pedersen and Hall conductances. For the elliptical irregularity stretched along $x$ (i.e. along the latitude) and located in the origin of coordinates, the disturbed electric fields, which arise due to polarization of the irregularity in the ambient electric field, $\boldsymbol{E}_{0}$, may be calculated as (see Safargaleev at al., 2000, and references therein):

$\boldsymbol{E}_{1}=\frac{a+b}{a-b} \frac{\Sigma_{0}+\Sigma_{0}^{*}+2 \Sigma_{\mathrm{w}}}{\Sigma_{1}-\Sigma_{0}} \frac{\mu \boldsymbol{E}_{0}+\boldsymbol{E}_{0}^{*}}{\mu \mu^{*}-1}-\boldsymbol{E}_{0}$

where $\mu=\frac{a+b}{a-b} \frac{\Sigma_{1}^{*}+\Sigma_{0}+2 \Sigma_{\mathrm{w}}}{\Sigma_{1}^{*}-\Sigma_{0}^{*}}$;

$\boldsymbol{E}_{2}=-\frac{1}{2}\left(\boldsymbol{E}_{1}+\frac{a+b}{a-b} \boldsymbol{E}_{1}^{*}\right)\left(\frac{1}{\sqrt{1-\frac{a^{2}-b^{2}}{z^{2}}}}-1\right)^{*}$

Equation (1) gives the value of the disturbed electric field, $\boldsymbol{E}_{1}$, inside the ellipse, and Eq. (2) describes the disturbance of electric field outside the inhomogeneity. Here $\Sigma_{\mathrm{w}}$ is effective conductivity of the magnetospheric plasma for propagating Alfvén wave, $\Sigma_{\mathrm{w}}=\left(\mu_{0} V_{\mathrm{A}}\right)^{-1}$, where $\mu_{0}$ is the vacuum magnetic permeability, $V_{\mathrm{A}}$ is the Alfvén velocity, $a$ and $b$ are the major and minor semi-axes of the ellipse. Symbol "** means the complex conjugate, the index 0 corresponds to the background values. Equations (1-2) are obtained by assuming that charges and field aligned currents are located on the ellipse periphery, and the undisturbed electric field $\boldsymbol{E}_{0}$ is uniform.

A local change of conductivity leads to the reconfiguration of the system of ionospheric currents and produces at the surface of the Earth a magnetic disturbance, which at some distance from the irregularity may be estimated as:

$\Delta B=\sim i \Delta J_{\mathrm{eq}} \sim i\left(\Sigma_{0}+\Sigma_{\mathrm{w}}\right) \boldsymbol{E}_{2}$

where imaginary unit $i$ provides the phase difference of $90^{\circ}$ between the equivalent ionospheric current, $J_{\text {eq }}$, and magnetic field.

Senior et al. (2007) showed that the Hall conductance and the conductance ratio, $\Sigma_{\mathrm{H}} / \Sigma_{\mathrm{P}}$, have the strongest associations with cosmic noise absorption and the Pedersen conductance is weakly related to the absorption. The similar behavior is demonstrated by ionospheric conductance in association with precipitation causing optical auroras in the nightside ionosphere (e.g. Safargaleev et al., 2000). So, for estimation of the field disturbances $\boldsymbol{E}_{1}$ and $\boldsymbol{E}_{2}$ we will assume background conductivity $\Sigma_{\mathrm{H} 0}=20 \mathrm{Ohm}^{-1}$, $\Sigma_{\mathrm{H} 0} / \Sigma_{\mathrm{P} 0}=2, \Sigma_{\mathrm{W}}=2$ and disturbed values (i.e. inside the irregularity) $\Sigma_{\mathrm{H} 1}=2 \Sigma_{\mathrm{H} 0}, \Sigma_{\mathrm{H} 1} / \Sigma_{\mathrm{P} 1}=4$.

The results of calculation of the disturbed electric field, $\boldsymbol{E}_{2}$, and associated disturbance in the northward component of geomagnetic field on the ground, $\Delta H$, are presented in Fig. 9 for four cases of orientation of ambient electric field. Upper panel in each figure is a sketch showing the orientation of the irregularity (gray area) with respect to $\boldsymbol{E}_{0}$ (open arrow). Horizontal bold line at the distance $1.5 b$ south of irregularity indicates the profile along which the disturbances of electric field (arrows) and magnetic field were calculated using Eqs. (1-3). Colored areas correspond to positive (green) and negative (yellow) values of $\Delta \mathrm{H}$. Here we focus mainly on the sign of $\Delta \mathrm{H}$, whereas calculated amplitudes of disturbances may not be reliable since we have no realistic data on $\boldsymbol{E}_{0}$, ionospheric conductivity, and changes caused by the precipitation.

Model situations (a) and (b) correspond to location of the irregularity in the late afternoon sector poleward or equatorward of the convection reversal boundary where the $\mathrm{N}$ $\mathrm{S}$ component of the ionospheric electric field dominates. Model situations (c) and (d) may be associated with location of the irregularity in the vicinity of the cusp where the horizontal component of the ambient electric field prevails (eastward or westward dependening on IMF $B_{\mathrm{Z}}$ orientation). Although the configuration of the electric field at high latitudes is rather complex, even this simplified model allows us to understand two observed features of PMD. Firstly, the magnetic disturbance caused by the irregularity in the same point may be of different polarity dependening on $\boldsymbol{E}_{0}$ orientation, which, in turn, is notably defined by IMF $B_{\mathrm{z}}$. We pointed out this finding in previous section. Secondly, the impulse character of variation might be conditioned by azimuthal propagation of the irregularity and adjusted stationary (in time) current system above the magnetometer. Indeed, one may 


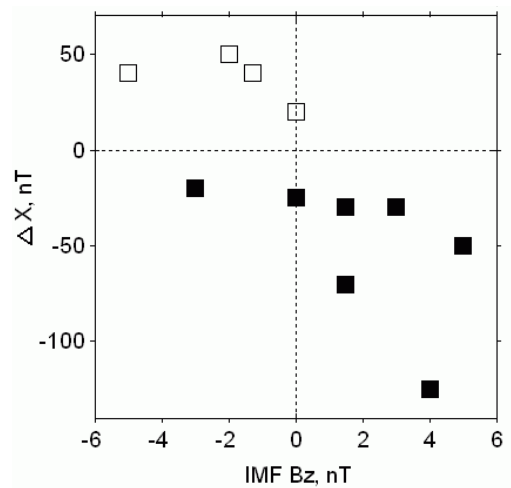

a

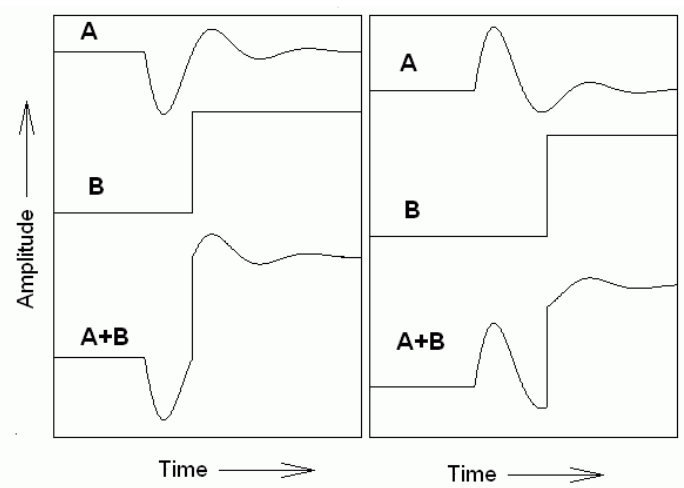

b

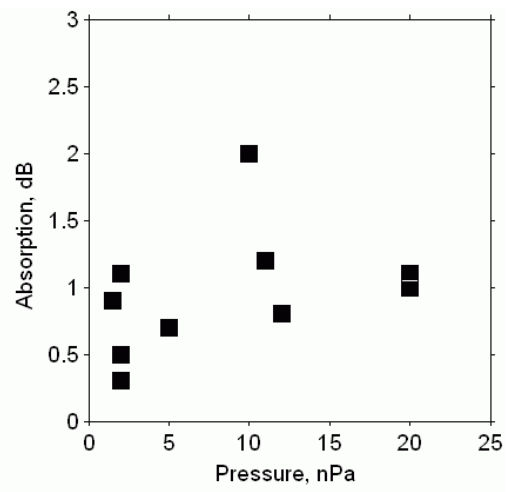

C

Fig. 8. (a) Dependence of the polarity of preliminary magnetic disturbance on the sign of IMF $B_{\mathrm{Z}}$ component; (b) sketch illustrating the presentation of the high-latitude disturbance as a sum of oscillations and step-like increase; (c) amplitude of SCA vs amplitude of SWPP.

easily infer this from the shape of H-disturbance in Fig. 9. This approach was applied earlier for explanation of magnetic spikes/Ps6 pulsations observed during the events of "omega auroras" (e.g. Kawasaky and Rostoker, 1979). As mentioned above, the impulse-like change of PMD may not be connected with temporal variation of ionospheric conductivity inside the irregularity since no corresponding changes was found in riometric data.

Note that model simulations may explain the non-perfect correlation between the sign of PMD and $B_{\mathrm{Z}}$ orientation (see Fig. 8a). Although the position of the observation point is fixed in space, the location of the ionospheric irregularity may change with respect to the orientation of the front of solar wind discontinuity that yields PMDs of different polarities even under the same IMF $B_{\mathrm{Z}}$ conditions.

In one case it was possible to test the model using some results of in situ measurements as input parameters. In Fig. 10a, two frames from the IMAGE satellite show that auroras responded to SWPP in pre-noon sector between $67-70^{\circ}$ MLAT. The DMSP F15 passed above this area $15 \mathrm{~min}$ before the onset in riometric absorption and positive magnetic impulse (see Table 1 and Fig. 7). The satellite detected the precipitation typical for central plasma sheet and also measured the electric field which we regard as ambient electric field.

The variations of two electric components along fragment of trajectory shown with white line on the top image are presented in Fig. 10b. Red arrow indicates the magnetic latitude of KIL. The electric field demonstrated the bi-polar variation in the south-north component at approximately $69^{\circ}$ MLAT, which may be a signature of the sheet of upward field aligned current on the poleward boundary of auroral oval (Kozlovsky et al., 2006). The averaging of the electric field over the interval between FAC and MLAT of KIL (i.e. over the auroral oval) gives $\boldsymbol{E}_{\mathrm{x} 0}=20 \mathrm{mV} / \mathrm{m}$ and $\boldsymbol{E}_{\mathrm{y} 0}=10 \mathrm{mV} / \mathrm{m}$. Here, x-axis is directed to the East, and direction of $y$ is to the North. Situation considered is close to that, which is presented in Fig. 9c: eastward component of $\boldsymbol{E}_{0}$ is twice the northward component and $B_{\mathrm{z}}$ is negative.
Sketch on the upper panel in Fig. 10c shows the collocation of irregularity (gray area) and observation point (red circle), open arrow is ambient electric field. The spatial distribution along the latitude of KIL (red line on the sketch) was obtained after substitution of above estimated $\boldsymbol{E}_{0}$ to Eqs. (13 ) and presented below the sketch. During the event, the magnetometer KIL was located very close to the eastern edge of the irregularity where our calculations give positive PMD, which is in accordance with observations. The impulse- like shape of PMD may be the effect of azimuthal (eastward) expansion of the irregularity.

\subsection{Psc 5 and sudden commencement absorption ex- cited by $\mathrm{SC}$}

Magnetic pulsations of Pc 5 frequency range are another interesting phenomenon following SWPP. These pulsations demonstrate signatures of the Alfvén waves both on the ground (Tverskaya and Khorosheva, 1982) and in space (Baumjohan et al., 1984; Eriksson et al., 2006) although the disturbance, which initiates Psc 5, is the compressional one. The problem of transformation of the energy from the magnetoacoustic oacoustic oscillations to the Alfvén mode is a fundamental problem of space physics rather than a particular case of generation of Pc 5 pulsations after SC. Among the numerous theories suggested (see, for instance, references in the paper by Eriksson et al., 2006) we note the generation of the Alfvén wave by the area of enhanced ionospheric conductivity (e.g. Kozlovsky et al., 1997, and references therein) since this mechanism is in good agreement with our previous suggestion (Safargaleev and Maltsev, 1987) and the observations discussed in the this paper.

In the presence of ambient electric field, the appearance of area of enhanced conductivity leads to the charge accumulation at its edges. Due to high plasma conductance in the direction of magnetic field, this polarization charge should escape from the ionosphere along the magnetic field lines, which give rise to the outgoing Alfvén wave. Also, such 

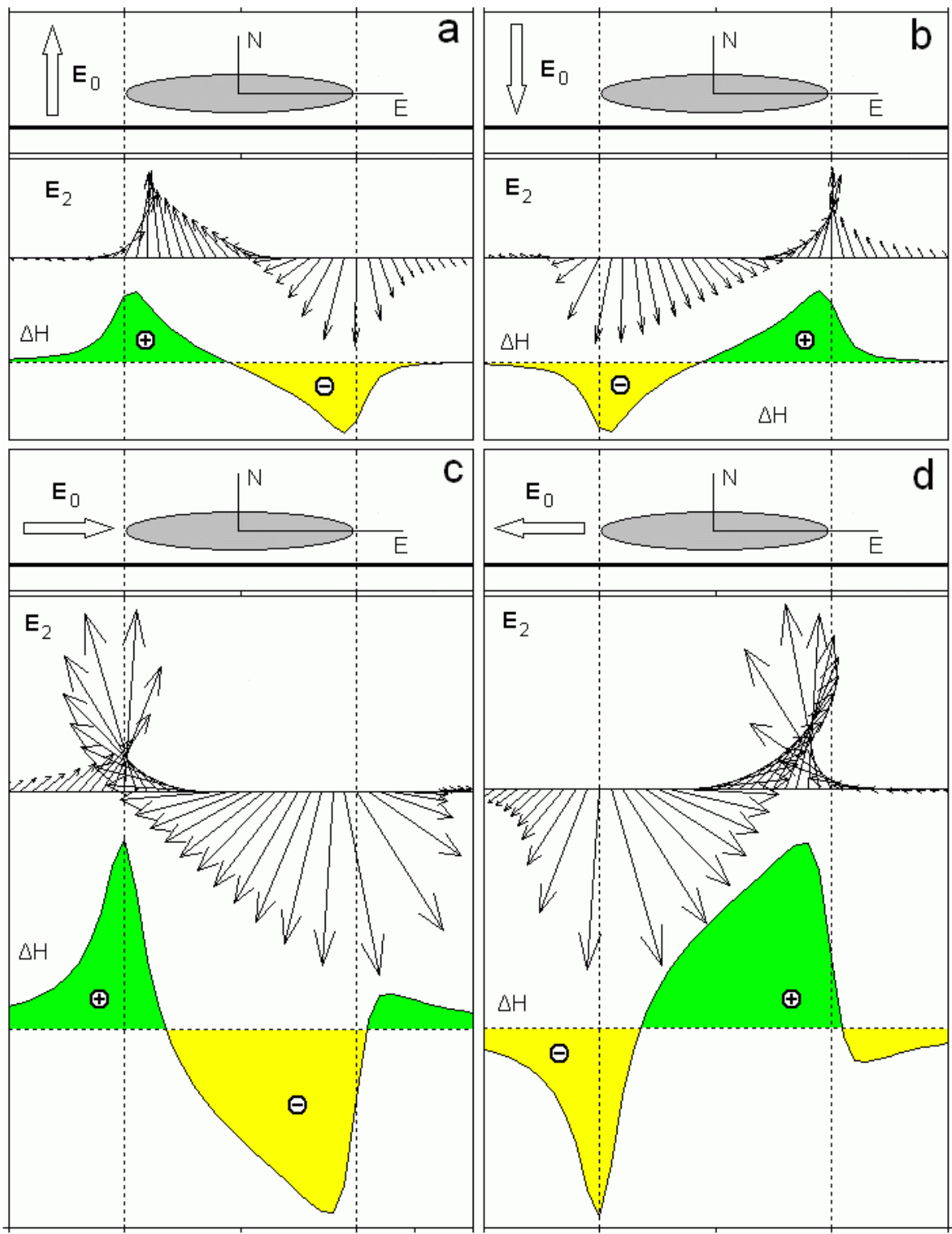

Fig. 9. Results of calculation of the polarization electric field in the ionosphere (arrows) and associated magnetic disturbance (highlighted curves) on the ground. Sketches show four uttermost variants of orientation of the irregularity (gray ellipse) relatively background electric field (open arrow), which my be realized under different $B_{\mathrm{Z}}$ orientation and at different MLT.

a wave should be launched from the conjugate ionosphere since SWPP stimulates precipitation in both hemispheres. The bouncing of the waves between the Northern and Southern hemispheres produces on the ground the train of pulsations with period defined by the Alfvén-wave transit time between the ionospheres.

Information about the period of pulsations is presented in the Table 1, ninth column. Sometimes no pulsations were detected or the amplitude of pulsations was very small, and there were occasions when the oscillation occurred it two modes simultaneously. The period of the modes is very close to that, which was inferred from the recent measurements on- board the Cluster satellites (Eriksson et al., 2006). Note that oscillations with period $120-140$ s fit our hypothesis on the ionospheric origin of Psc 5 pulsations better than 60-s oscillations, since the time of a few minutes seems to be closer to the time of Alfvén wave propagation between high latitude ionospheres (see for instance, Safargaleev et al., 2003).

The electric field of the outgoing Alfvén wave is a combination of the polarization electric fields $\boldsymbol{E}_{1}$ and $\boldsymbol{E}_{2}$ determined by Eqs. (1-2). In accordance with Eq. (2), the field outside the irregularity decreases as $1 / z^{2}$, where $z$ is complex analogue of the distance from the irregularity. So, the Alfvén oscillations will be observed in the area, which is restricted at 


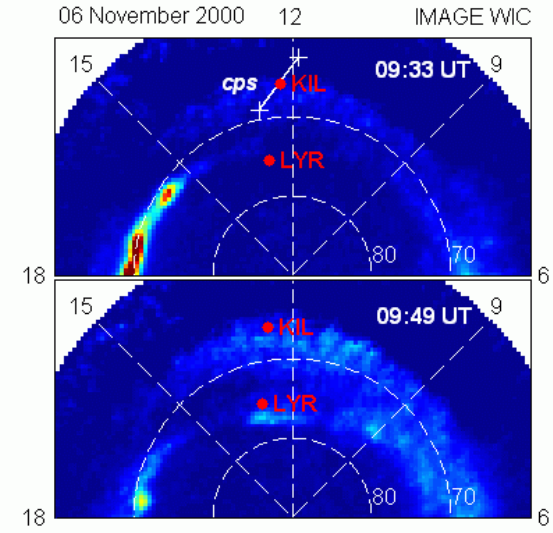

a

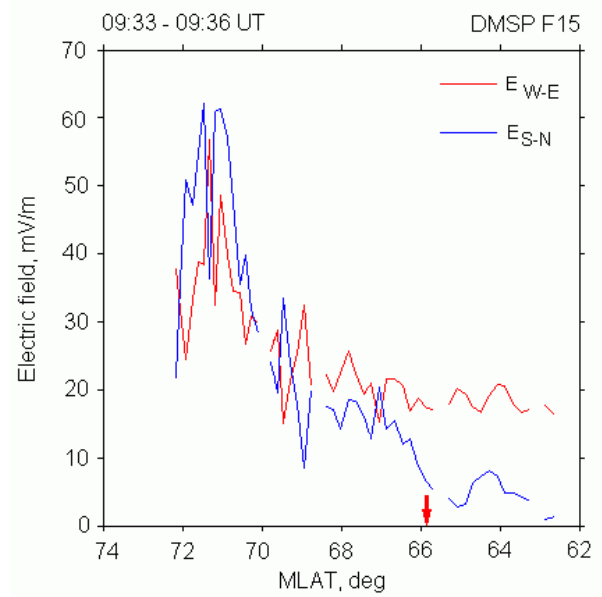

b

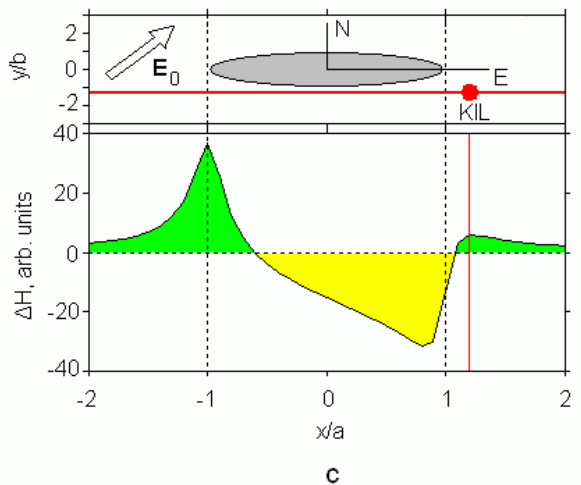

Fig. 10. Model calculations for the event when the direct satellite measurements of the electric field in the place where the irregularity then appeared were available. (a) Images of electron auroras showing the fragment of DMSP F15 trajectory used for definition of the background electric field (top) and location of observatories and enhanced auroras (bottom); (b) variations of the electric components in the direction along (red) and perpendicular (blue) the irregularity; (c) spatial distribution of magnetic disturbance on the ground, green areas correspond to positive variation and yellow area correspond to negative one. Position of KIL indicated with red circle.

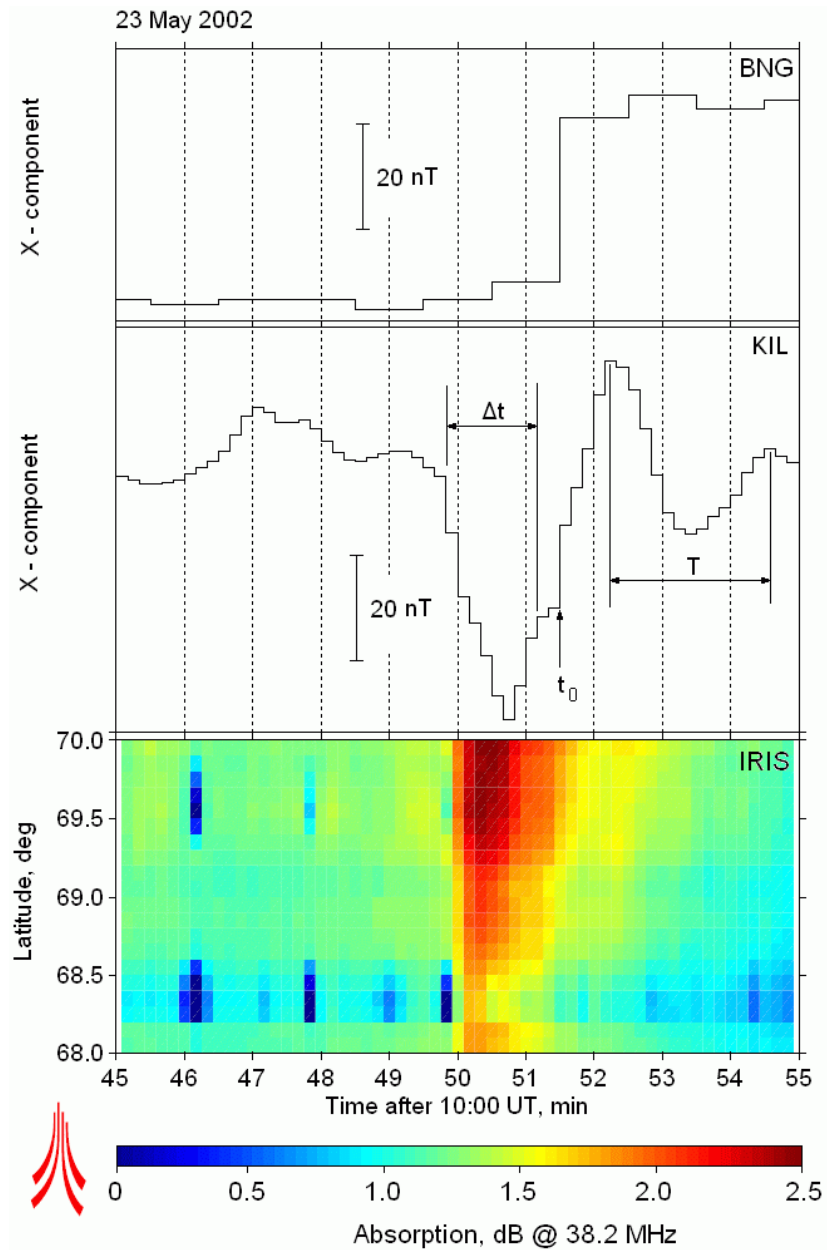

Fig. 11. Complex form of the SC-initiated magnetic disturbance. $\Delta t$ is duration of preliminary impulse, $t_{0}$ indicates the time of arrival of the front of MHD-disturbance to the ionosphere, $T$ is the period of pulsations.

least in the meridional direction on the ground and radial direction in space that is consistent with Tverskaya and Khorosheva (1982) and Eriksson et al. (2006).

Figure 11 summarizes the discussion on the shape of preliminary magnetic disturbance. It is suggested that the shape is defined by three factors. The first one is the disturbance of the ionospheric current system by the enhanced particle precipitation. This yields the negative or positive impulse of $\sim 1$ min duration (indicated as $\Delta t$ in Fig. 11). The second one is the front of compressional disturbance, which reaches the ionosphere $\sim 1$ min after the particles (time $t_{0}$ in Fig. 11). The third one is the Alfvén oscillations triggered by the appearance of local ionospheric irregularity. Period of pulsations is a few minutes (denoted as $T$ in Fig. 11). 


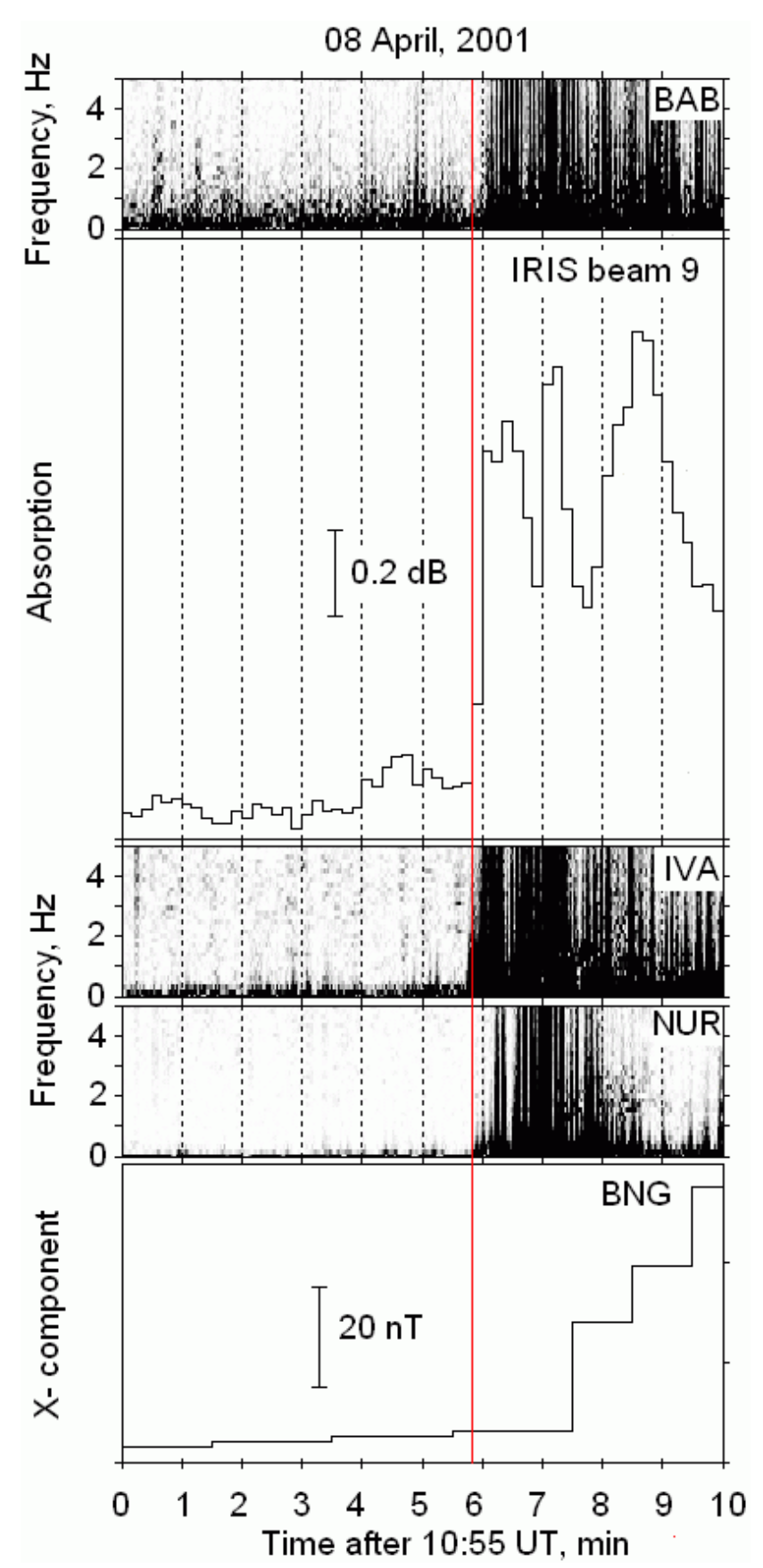

Fig. 12. Broadband enhancement of the ULF noise on meridional array of induction magnetometers. Red line indicates the time of SCA.

\subsection{SC-initiated magnetic activity in the frequency range $0.1-3 \mathrm{~Hz}$}

In accordance with Tepley and Wentworth (1962) and Safargaleev et al. (2002), approximately $20 \%$ of SWPPs are accompanied with excitation of a narrowband burst (or series of bursts) of rising frequency like that shown in Fig. 2b and Fig. 5 (bottom panel). One more known response to the SWPP in this frequency range is an increase of amplitude and carrier frequency of pre-existing Pc 1 pulsations of the "pearls" type (e.g. Kangas et al., 1998). In this paper, we emphasize the broadband enhancement of the ULF activity that occurred simultaneously with positive bay in riometric absorption and preliminary magnetic disturbance as a new form of geomagnetic response to SWPP.

Figure 12 shows the SC-initiated broadband magnetic enhancement at the meridional array of induction magnetometers. At first, the enhancement was observed at IVA. The moment is indicated with red vertical line. A few seconds later it was detected at BAB and NUR located $\sim 1100 \mathrm{~km}$ north and $\sim 900 \mathrm{~km}$ south of IVA, respectively. Satellite DMSP F14 flew above BAB at 09:59 UT (i.e. three minutes after ULF broadband enhancement) and observed precipitation that are typical for the boundary plasma sheet (DMSP data are not presented here). This means that BAB, as well as IVA and NUR, was on closed magnetic field lines. Hence, the lag of signal both poleward and equatorward IVA might be conditioned rather by the expansion of ULF-disturbance in the ionospheric waveguide away from IVA than propagation of its source in the magnetosphere in radial direction. The figure also shows that the magnetic enhancement at IVA coincides in time with enhancement in riometric absorption at $\mathrm{KIL}$, which is the earliest response to sudden magnetosphere compression.

The above listed features of the broadband ULF enhancement give an opportunity to use the meridional chain of induction magnetometers for accurate timing of the impact of solar wind irregularity to the magnetopause even if the absorption data are absent for some reasons. As an example, we consider one more event (28 October 2000), which was not presented in the Table 1 because of the noise in IRIS data. Sudden compression was accompanied by intensification of pre-existing Pc 1 "pearls", broadband ULFenhancement and the burst of rising frequency (Fig. 13a), as well as proton auroras (Fig. 13b). The auroral response was mentioned earlier in the paper by Fuselier et al. (2004) among other "transient dayside subauroral proton precipitation" events produced by rapid changes in solar wind dynamic pressure. Broadband enhancement at 09:54 UT is faint (see for comparison Fig. 12) but this allows us to identify the burst of rising frequency and define the time of its onset with higher accuracy than, for instance, for the event presented in Fig. 5. Enhancement begins almost simultaneously with a negative preliminary impulse at KIL and intensification of Pc 1 "pearls" at OUL. The burst is delayed by $100 \mathrm{~s}$ (see Fig. 13c). Although the proton auroras appeared in IMAGE data at the same time as the burst (see Fig. 13b), we can not claim that they started simultaneously because of the low temporal resolution of IMAGE data.

No burst-like disturbances were seen both poleward and equatorward of KIL (see Figs. 2 and 13c), which is consistent with the assumption that the generation region of the 


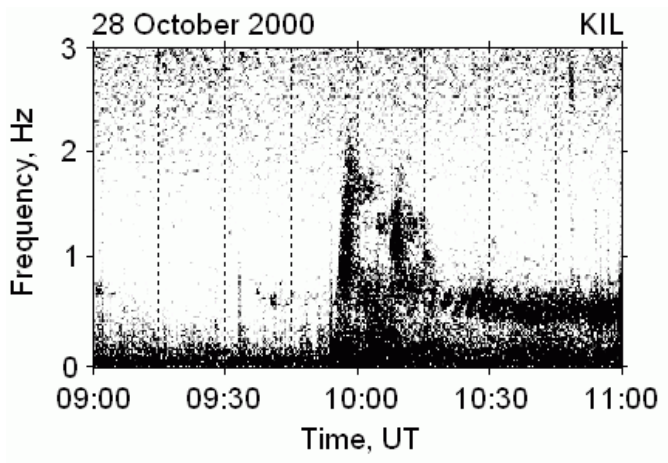

a

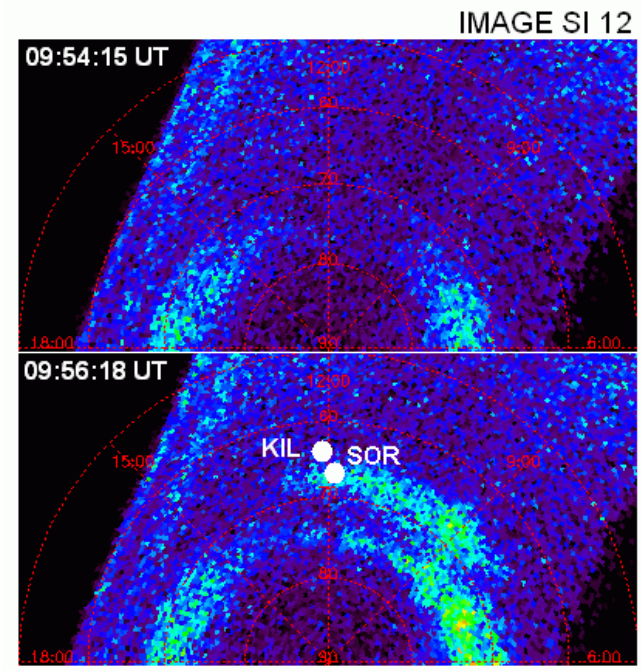

b

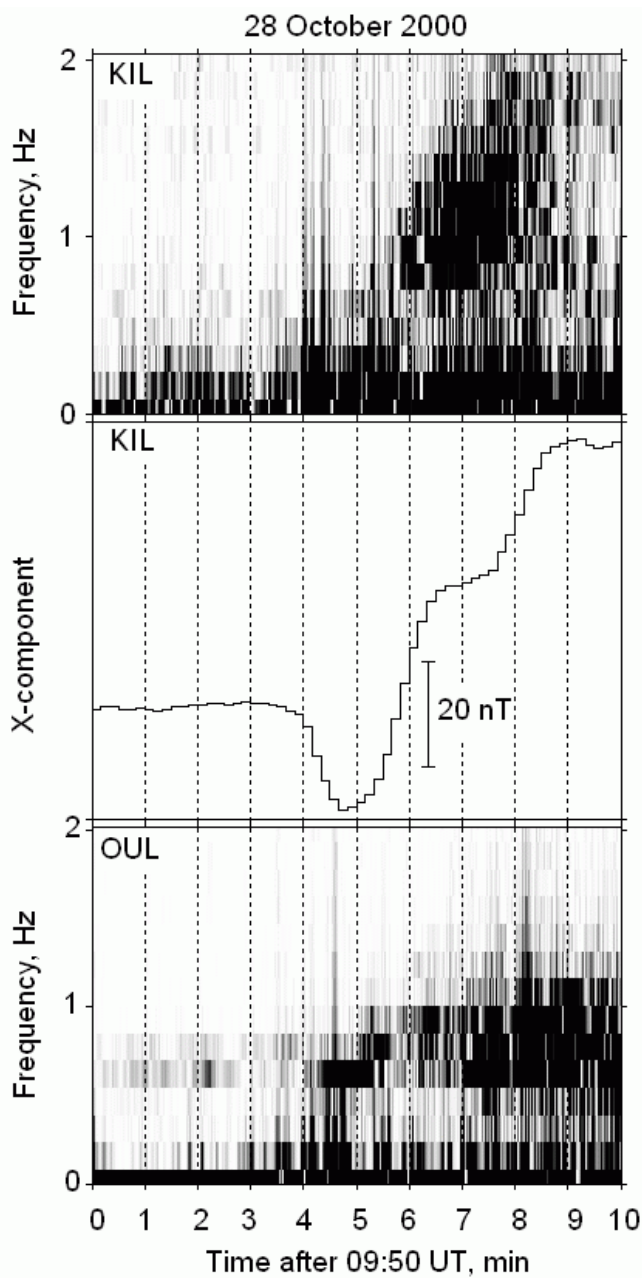

C

Fig. 13. (a) General form of the response to SWPP in frequency band above $0.1 \mathrm{~Hz}$; (b) SC-associated transient dayside subauroral proton precipitation; (c) from top to bottom: broadband enhancement and rising burst at high latitudes, preliminary impulse at KIL and intensification of pre-existing pulsations of the "pearls" type at low latitudes.

bursts is limited in radial direction in the magnetosphere ( $\mathrm{Sa}$ fargaleev et al., 2002). Pulsations of Pc 1 band are commonly accepted as the Alfvén waves generated via the development of electromagnetic ion-cyclotron (EMIC) instability. Proton auroras are also associated with this instability since they are produced by the particles scattered by the EMIC-waves. Hence, we can suppose that the SC-stimulated protons auroras in Figs. 6 and 13b are ionospheric "projection" of the generation region for rising bursts shown in Figs. 5 (bottom panel) and 13c (upper panel).

The observed delay of the bursts relative to the absorption enhancement may be conditioned by two factors. First, the condition for development of EMIC instability, which is responsible for rising burst generation, may differ from that for electromagnetic electron-cyclotron (EEC) instability causing electron precipitation and increase of riometric absorption, although both instabilities have the plasma anisotropy as a mutual source of the free energy. Indeed, the growth rate for EEC and EIC instabilities depends on many factors, which makes difficult their comparative analysis.

Second factor is a difference in propagation time of the electrons and EIC-waves from the generation region (equatorial plane of the magnetosphere) to the ionosphere. This issue was discussed earlier by Safargaleev et al. (2003) and is illustrated on the sketch in Fig. 14a. Magnetosphere compression leads to the development of plasma anisotropy in the equatorial plane (dark area), which, in turn, gives rise to both EEC and EIC instabilities (top panel). The EEC-waves scatter the electrons to the ionosphere (thin black arrow), due to which the absorption and ionospheric conductivity enhance and Alfvén impulse is launched to the magnetosphere (red arrow on the middle panel). After the time interval corresponding to the propagation time of the EIC wave (bold black arrow) between equatorial plane and ionosphere, the wave is 


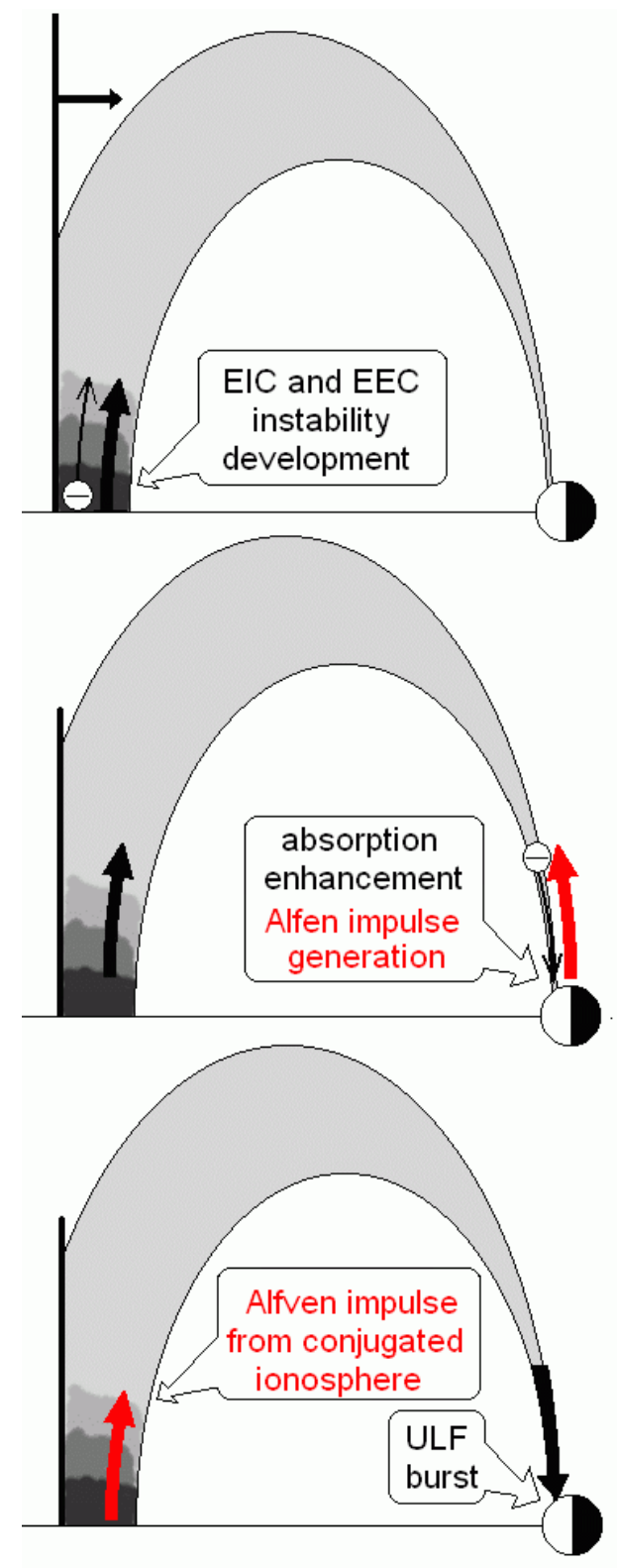

a
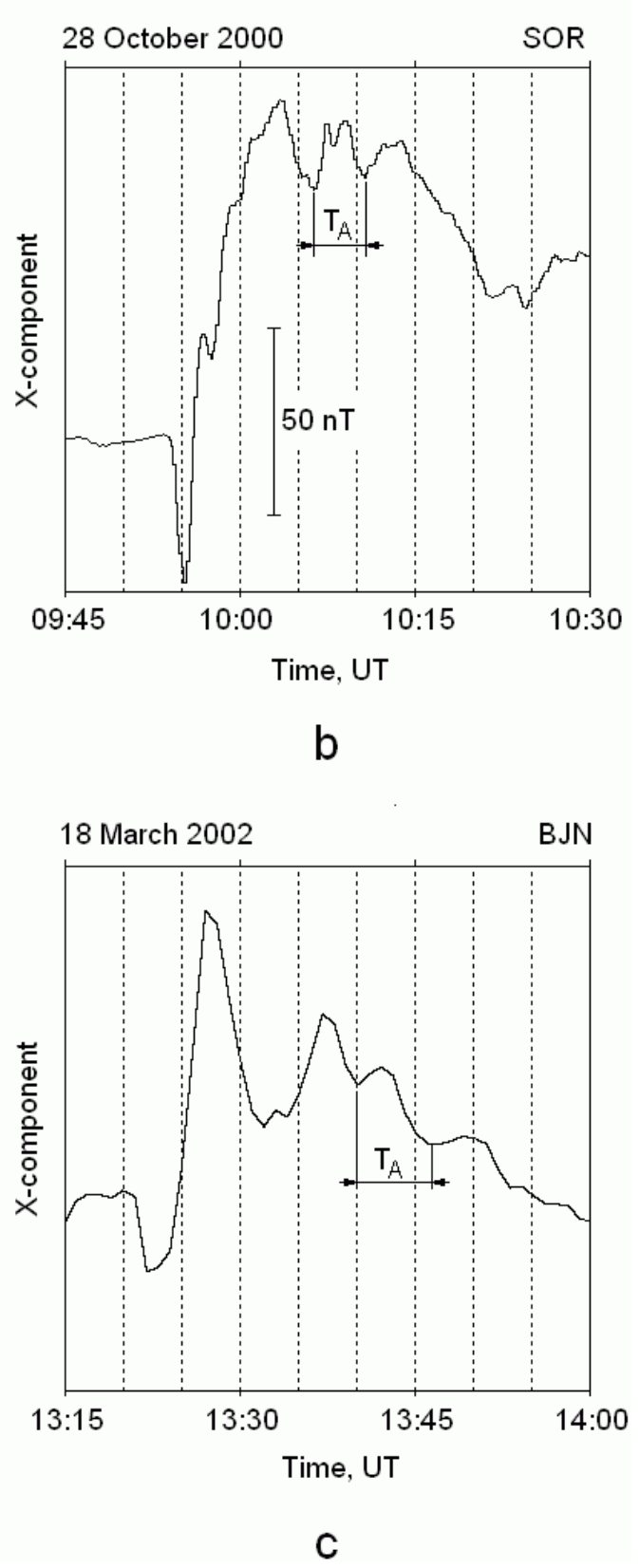

Fig. 14. (a) Sketch showing the reason of the lag of rising burst relatively SCA and generation and propagation of the Alfvén impulses (red arrows); (b, c) magnetic pulsations at observatories located just below the ionospheric irregularity. Period of pulsations, $T_{\mathrm{A}}$, corresponds to the propagation time of the Alfvén impulse between conjugated ionospheres.

detected on the ground (bottom panel) as rising burst. Assuming that the Alfvén impulse and EIC-wave propagate at the same velocity, we indicate on this panel also the Alfvén impulse launched from the conjugate ionosphere. We do not discuss here the proton precipitation since we can not perform correct timing of proton aurora enhancement for the events considered.

Safargaleev et al. (2003) suggested the method for estimation of the period for resonant (Alfvén) oscillations assum- ing the time lag of the rising burst to be close to the time of the Alfvén wave half-hop between conjugate ionospheres. Our observations support this suggestion. Indeed, during the event on 28 October 2000, the proton auroras occurred at latitudes of SOR (see Fig. 13b), and the time lag of about $2 \mathrm{~min}$ inferred from the sonogram in Fig. 13c is close to the half of period of oscillations at this station denoted in Fig. 14b as $T_{\mathrm{A}}$. During the event on 18 March 2002, the proton auroras occurred at latitudes of BJN (see Fig. 6a), and the time 
lag of about 3 min (see Fig. 5) is close to the half-period of oscillations at this station (see Fig. 14c). In our reasoning we neglected the propagation time of the Alfvén wave in the ionospheric waveguide from the place of the incidence in the ionosphere to the observational point. In accordance to estimations by Safargaleev et al. (2004), this time is of the order of the temporal resolution of riometric and IMAGE magnetic data.

The present method gives the observed value of the propagation time of the Alfvén wave along the magnetic field lines instead of commonly used theoretical estimations or the results of in-situ measurements but in the direction perpendicular to the magnetic field (e.g. Wilken et al., 1998). The result obtained may be of a practical importance. At auroral latitudes it may be taken into account in the heating experiments aimed at artificial excitation of the magnetosphere eigen-mode oscillations. At higher latitudes the time lag may be regarded as the response time of the dayside polar ionosphere to the magnetopause processes because the information about these processes is transferred by Alfvén waves. One can estimate also an averaged Alfvén wave velocity along the magnetic field lines and use this to specify some theoretical models (for instance, the models of Pc 1 "pearls" pulsations by Trakhtengerts et al., 2000; preliminary impulse of SC by Tamao, 1964; etc).

\section{Summary}

We have examined several cases of magnetosphere compression by solar wind pressure pulses using a set of instruments in the around-noon sector. We have found that the increase in the riometric absorption occurred simultaneously with the beginning of positive or negative magnetic variation in auroral zone and broadband enhancement of magnetic activity in the frequency range above $0.1 \mathrm{~Hz}$. Herewith, the magnetic variations were observed prior to the step-like increase in the magnetic $\mathrm{H}$-component at equatorial stations, so that the negative magnetic variation resembled a typical preliminary impulse of SC. The sign of the disturbance demonstrated an anti-correlation with the sign of IMF $B_{\mathrm{Z}}$-component.

For some of the considered events, the IMAGE satellite data on electron auroras were available and showed the precipitation of auroral electrons together with electrons causing an increase in riometric absorption. Precipitations in a wide energy range could lead to the local enhancement of ionospheric conductivity and reconfiguration of the current system.

Using the simple model of ionospheric irregularity, we have calculated the polarization electric field outside the irregularity and corresponding magnetic disturbance on the ground. The calculations show that the sign of disturbance depends on orientation of the background electric field and location of the observation point in respect to the irregularity. Note, that both factors may be regulated by the conditions in the interplanetary medium, in general, and by the sign of IMF $B_{\mathrm{Z}}$-component, in particular. For one case of direct measurements of electric field in the place where the electron auroras (i.e. ionospheric irregularity) were present, the sign of calculated disturbance corresponded to the observed one.

Since the velocity of precipitating electrons is much larger than that for the MHD-disturbance causing the step-like magnetic enhancement on the equatorial stations, we suggest the ionospheric irregularity as a source of the preliminary impulse of $\mathrm{SC}$ at high latitudes.

The ionospheric irregularity could be also a source of the Alfvén-like pulsations following the SC. In such "ionospheric" approach, the period of pulsations is defined by the propagation time of the Alfvén wave between the conjugate hemispheres. Using the method of estimation of propagation time suggested earlier by Safargaleev et al. (2003) we have found the pulsations of an appropriate period in our data. However, the ionospheric mechanism does not explain the SC-initiated pulsations with smaller period, which were also observed in the course of our investigation, as well as reported by other authors (e.g. Eriksson et al., 2006).

When the absorption measurements are performed with high temporal resolution, they may be used for the accurate timing of the impact of solar wind irregularity to the magnetopause. We have found that the absorption started to increase simultaneously with the enhancement of the broadband magnetic disturbance. So, the additional instrument, which might be used for the timing purposes, is the meridional chain of the induction magnetometers.

We have also found that SC-associated broadband bursts of rising frequency in the band of Pc 1 magnetic pulsations correlated with the enhancements of proton auroras. This indicates that the EIC instability should lead both to the burst generation and proton scattering. However, for detail study of this phenomenon the data on proton precipitations are needed of better temporal resolution than the 2-min images taken from the IMAGE satellite.

It is known that precipitations in the dayside respond to both SWPP and IMF change. In our study we emphasized the disturbances that occurred on the ground during 1-3 min after the solar wind irregularity hits the magnetopause. In accordance with Kozlovsky et al. (2007), IMF affects the auroras 6-20 min after SI. Hence, the preliminary impulse, broadband increase of magnetic disturbances above $0.1 \mathrm{~Hz}$, as well as sudden commencement absorption and aurora enhancement may be associated with sudden magnetosphere compression rather than with IMF variations accompanying almost all SWPP events considered.

Acknowledgements. We thank the Finnish Meteorological Institute and other institutes who maintain the IMAGE magnetometer array. The Finnish induction magnetometer chain is operated by Sodankylä Geophysical Observatory (SGO) and the induction magnetometer on Svalbard is operated by Polar Geophysical Institute. The DMSP particles detectors were designed by D. Hardy 
(AFRL), and data obtained from JHL/APL. We gratefully acknowledge the Center for Space Sciences at the University of Texas at Dallas and the US Air Force for providing the DMSP thermal plasma data. The BNG and AAE magnetic data are from the Kyoto World Data Center C-2 in Kyoto, Japan. The authors acknowledge S. B. Mende and the IMAGE FUV team for providing the NASA IMAGE satellite data. The ACE and Wind data on the interplanetary medium are taken from CDAWeb (data providers are D. J. McComas at SWRI, N Nesa at Bartol Research Institute and K.Oglive at NASA GSFC). The Imaging Riometer for Ionospheric Studies (IRIS) is operated by Lancaster University in collaboration with SGO and is supported by Science and Techonolgy Facilities Council (STFC), UK. The Academy of Finland supported work of V. Safargaleev (project 122528) and A.Kozlovsky and T. Turunen (project 115920). The work of V. Safargaleev was partially supported by the Program 16 of Presidium of RAS. We thank T. Raita, J. Manninen (SGO) and N. Kudryashova (PGI) for assistance.

Topical Editor R. Nakamura thanks A. Shinbori and V. Pilipenko for their help in evaluating this paper.

\section{References}

Araki, T.: Global structure of geomagnetic sudden commencements, Plant. Space Sci., 25, 373-384, 1977.

Araki, T., Iyemory. T., Tsunomura, S., Kamei, T., and Maeda, H.: Detection of an ionospheric current for the preliminary impulse of the geomagnetic sudden commencement, Geophys. Res. Lett., 8, 341-344, 1982.

Araki, T.: A physical model of the geomagnetic sudden commencement, in: Solar Wind Source of Magnetospheric Ultra-LowFrequency Waves, Geophys. Monogr. Ser., 81, edited by: Engebretson, M., Takahashi, K., and Scholer, M., AGU, Washington, D.C., 183-200, 1994.

Baumjohann, W., Junginger, H., Haerendel, G., and Bauer, O. H.: Resonant Alfvén waves ecxited by a sudden impulse, J. Geophys. Res., 89, 2765-2769, 1984.

Brittnacher, M., Wilber, M., Fillingim, M., Chua, D., Parks, G., Spann, J., and Germany, G.: Global auroral response to a solar wind pressure pulse, Adv. Space Res., 25(7-8), 1377-1385, 2000.

Brown, R. R., Hartz, T. R., Landmark, B., Leinbach, T., and Ortner, J.: Large-scale electron bombardment at the atmosphere at the sudden commencement of geomagnetic storm, J. Geophys. Res., 66, 1035-1041, 1961.

Eriksson, P. T. I., Blomberg, L. G., Schaefer, S., and Glassmeier, K.-H.: On the excitation of ULF waves by solar wind pressure enhancements, Ann. Geophys., 24, 3161-3172, 2006, http://www.ann-geophys.net/24/3161/2006/.

Fujita, S., Tanaka, T., Kikuchi, T., Fujimoto, K., Hosokawa, K., and Itonaga, M.: A numerical simulation of the geomagnetic sudden commencement: 1 . Generation of the field-aligned current associated with the preliminary impulse, J. Geophys. Res., 108, 12, doi:10.1029/2002JA009407, 2003.

Fuselier, S. A., Gary, S. P., Thomsen, M. F., Claflin, E. S., Hubert, B., Sandel, B. R., and Immel, T.: Generation of transient dayside subauroral proton precipitation, J. Geophys. Res., 109, A12227, doi:10.1029/2004JA010393, 2004.

Hasegawa, A. and Chen, L.: Theory of magnetic pulsations, Space. Sci. Rev., 16, 347-359, 1974.
Hubert, B., Gérard, J. C., Fuselier, S. A., and Mende, S. B.: Observation of dayside subauroral proton flashes with the IMAGE-FUV imagers, Geophys. Res. Lett., 30(3), 45-1, doi:10.1029/2002GL016464, 2003.

Kangas, J., Guglielmi, A., and Pokhotelov, O.: Morphology and physics of short-period magnetic pulsations, Space Sci. Rev., 83, 435-512, 1998.

Kawasaki, K. and Rostoker, G.: Perturbation magnetic fields and current systems associated with eastward drifting auroral structures, J. Geophys. Res., 84, 1464-1480, 1979.

Kikuchi, T. and Araki., T.: Comments on "Propagation of the preliminary reverse impulse of sudden commencements to low latitudes” by P. J. Chi et al., J. Geophys. Res., 107(12), 1433, doi:10.1029/2002JA009261, 2002.

Kozlovsky, A. E. and Lyatsky, W. B.: Alfvén wave generation by disturbance of ionospheric conductivity in the field-aligned current region, J. Geophys. Res., 102, 17287-17304, 1997.

Kozlovsky, A., Koustov, A., Lyatsky, W., Kangas, J., Parks, G., and Chua, D.: Ionospheric convection in the postnoon auroral oval: SuperDARN and Polar UVI observations, J. Geophys. Res., 107(12), 1473, doi:10.1029/2001JA009220, 2002.

Kozlovsky, A., Safargaleev, V., Østgaard, N., Turunen, T., Koustov, A., Jussila, J., and Roldugin, A.: On the motion of dayside auroras caused by a solar wind pressure pulse, Ann. Geophys., 23, 509-521, 2005,

http://www.ann-geophys.net/23/509/2005/.

Kozlovsky, A. E., Nilsson, H., and Safargaleev, V. V.: Complex study of the auroral arc dynamics and ionosphere plasma convection in prenoon hours, Geomagnetism and Aeronomy, 46(4), 473-484, 2006 (Engl. transl.).

Kozlovsky, A., Meurant, M., and Turunen, T.: Changes of dayside auroral distribution caused by a solar wind pressure pulse and associated interplanetary magnetic field disturbances, Ann. Geophys., 25, 929-940, 2007, http://www.ann-geophys.net/25/929/2007/.

Liou, K., Wu, C.-C., Lepping, R. P., Newell, P. T., and Meng, C.-I.: Midday sub-auroral patches (MSPs) associated with interplanetary shocks, Geophys. Res. Lett., 29(16), 18-1, doi:10.1029/2001GL014182, 2002.

Manninen, J., Turunen, T., Lubchich, A., Titova, E., and Yahnina, T.: Relations of VLF emissions to impulsive electron precipitation measured by EISCAT radar in the morning sector of auroral oval, J. Atmos. Terr. Phys., 58, 97-106, 1996.

Maltsev, Yu. P., Leontyev, S. V., and Lyatsky W. B.: Pi-2 pulsations as a result of evolution of an Alfvén impulse originating in the ionosphere during a brightening of aurora, Planet. Space Sci., 22, 1519-1533, 1974.

Nielsen, E. and Honary, F.: Observations of ionospheric flows and particle precipitation following a Sudden Commencement, Ann. Geophys., 18, 908-917, 2000, http://www.ann-geophys.net/18/908/2000/.

Nishida, A.: Ionospheric screen effect and storm sudden commencement, J. Geophys. Res., 69, 1861-1874, 1964.

Ortner, J. B., Hultqvist, B., Brown, R. R., Hartz, T. R., Holt, O., Landmark, B., Hook, J. L., and Leinbach, H.: Cosmic noise absorption accompanying geomagnetic storm sudden commencement, J. Geophys. Res., 67, 4169-4186, 1962.

Ranta, A. and Ranta, H.: Storm sudden commencement observed in ionospheric absorption, Planet. Space Sci., 38, 365-372, 1990. 
Safargaleev, V. V. and Maltsev, Yu. P.: Generation of a preliminary impulse and long-period pulsations during an SI, Geomagnetism and Aeronomy, 27(2), 211-215, 1987 (Engl. transl.).

Safargaleev, V., Lyatsky, W., Gazey, N. G., Smith, P. N., and Kriviliov, V.: The response of the azimuthal component of the ionospheric electric field to auroral arc brightening, Ann. Geophys., 18, 65-73, 2000, http://www.ann-geophys.net/18/65/2000/.

Safargaleev, V., Kangas, J., Kozlovsky, A., and Vasilyev, A.: Bursts of ULF noise excited by sudden changes of solar wind dynamic pressure, Ann. Geophys., 20, 1751-1761, 2002, http://www.ann-geophys.net/20/1751/2002/.

Safargaleev, V. V., Pchelkina, E. V., and Vasilyev, A. N.: The time of Alfvén wave propagation as inferred from ground based riometer and magnetic data, Geomagnetism and Aeronomy, 43(3), 320325, 2003 (Engl. transl.).

Safargaleev, V. V., Pchelkina, E. V., Kudryashova, N. V., Voronin, A. I., and Kozlovsky, A. E.: Propagation velocity of $0.2-5 \mathrm{~Hz}$ waves in the ionospheric waveguide, Geomagnetism and Aeronomy, 44(5), 559-566, 2004 (Engl. transl.).

Saito, T. and Matsushita, S.: Geomagnetic pulsations associated with sudden commencements and sudden impulses, Planet. Space Sci., 15, 573-587, 1967.

Senior, A., Kavanagh, A. J., Kosch, M. J., and Honary, F.: Statistical relationships between cosmic radio noise absorption and ionospheric electrical conductances in the auroral zone, J. Geophys. Res., 112, A11301, doi:10.1029/2007JA012519, 2007.
Tamao, T.: A hydromagnetic interpretation of geomagnetic SSC* Rep. Ionos. Space Res. Jpn., 18, 16-31, 1964.

Tepley, L. R. and Wentworth, R. C.: Hydromagnetic emissions, Xrays, and electron bunches: 1.Experimental results, J. Geophys. Res., 67, 3317-3324, 1962.

Trakhtengerts, V. Y., Demekhov, A. G., Polyakov, S. V., Belyaev, P. P., and Rapoport, V. O.: A mechanism of Pc 1 pearl formation based on the Alfvén sweep maser, J. Atmos. Solar-Terr. Phys., 62, 231-235, 2000.

Tverskaya, L. V. and Khorosheva, O. V.: Source of the packets of dumped long-period magnetic pulsations, Geomagnetism and Aeronomy, 22, 676-680, 1982.

Yahnin, A., Titova, E., Lubchich, A., Bösinger, T., Manninen, J., Turunen, T., Hansen, T., Troshichev, O., and Kotikov, A.: Dayside high latitude magnetic impulsive events: their characteristics and relationship to sudden impulses, J. Atmos. Terr. Phys., 57, 1569-1582, 1995.

Zhou, X. and Tsurutani, B. T.: Rapid intensification and propagation of the dayside aurora: Large scale interplanetary pressure pulses (fast shocks), Geophys. Res. Lett., 26, 1097-1100, 1999.

Wilken, B., Goertz, C. K., Baker, D. N., Higbie, P. R., and Fritz, T. A.: The SSC on July 29, 1977 and its propagation within the magnetosphere, J. Geophys.Res., 87, 5901-5910,1982. 